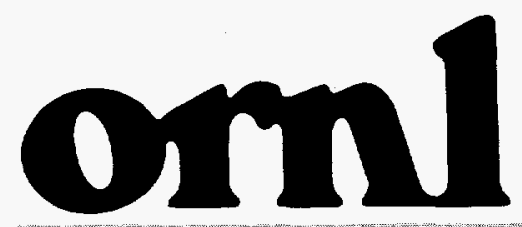

oAK RIDGE NATIONAL LABORATORY

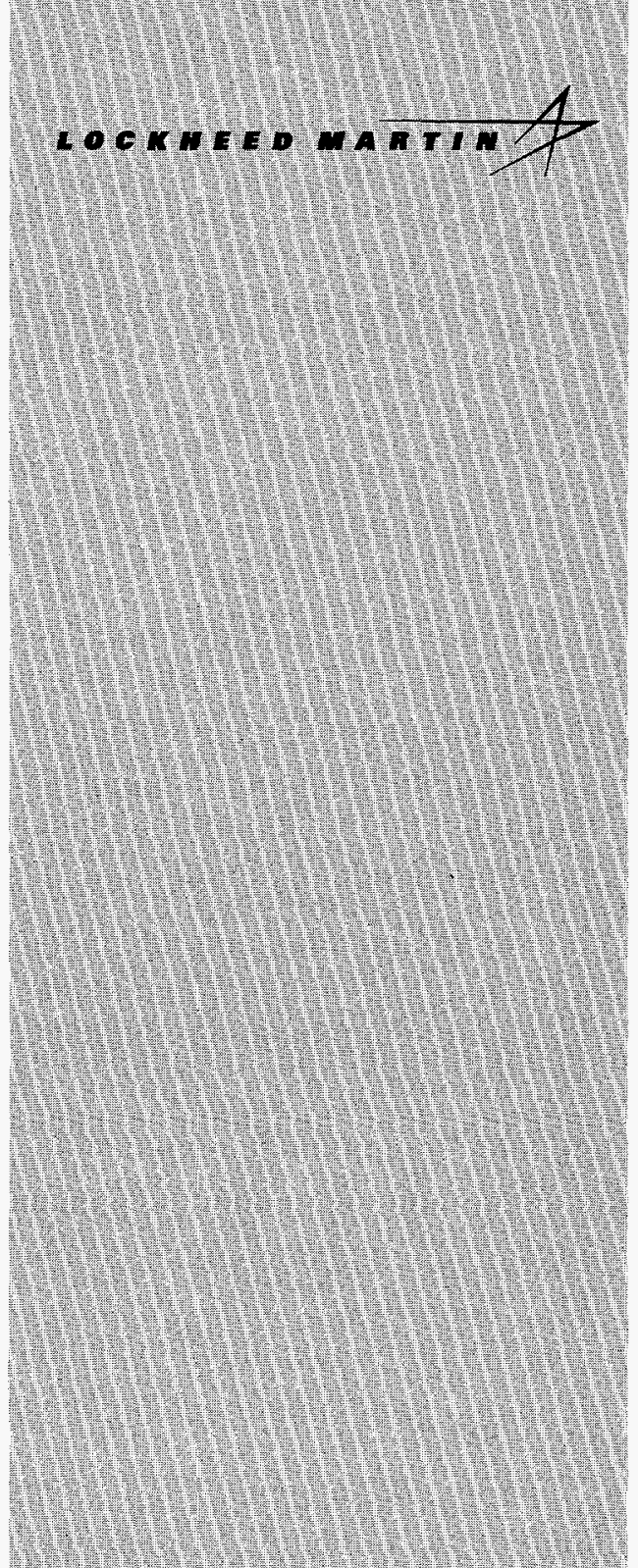

UANAGED AND OPERATED BY LOCKHEED MARTIN ENERGY RESEARCH CORPORATION FORTHE UNTED STATES DEPARTIIENT OF ENERGY

\section{DEVELOPMENT OF METAL-CLAD FILLED EVACUATED PANEL SUPERINSULATION}

Final Report for CRADA Number ORNL 93-0192

K. E. Wilkes

J. P. Strizak

F. J. Weaver

J. E. Besser

D. L. Smith

Aladdin Industries, Inc.

March 1997

Prepared by

OAK RIDGE NATIONAL LABORATORY

Oak Ridge, Tennessee 37831

Managed by

LOCKHEED MARTIN ENERGY RESEARCH CORP. for the

U.S. DEPARTMENT OF ENERGY under contract DE-AC96OR22464 


\section{DISCLAIMER}

This repon was prepared as an account of work sponsored by an agency of the United States Government. Neither the United States Government nor any agency thereot, nor any of their employees, makes any warranty. express or implied, of assumes any legal liability or responsibility lor the accuracy, completeness, or use fulness of any information, apparatus. product, or process disclosed, or represents that its use would not infringe privately owned rights. Reference herein to any specific commercial product. process, or service by trade name, trademark, manufacturer, of otherwise. does not necessarily constitute or imply its endorsement. recommendation, or favoring by the United States Government or any agency thereof. The views and opinions of authors expressed herein do not necessarily state or reflect those of the United States Government or any agency thereot. 


\section{DISCLAIMER}

Portions of this document may be illegible electronic image products. Images are produced from the best available original document. 
Metals and Ceramics Division

CRADA Final Report

for CRADA Number ORNL 93-0192

DEVELOPMENT OF METAL-CLAD FILLED EVACUATED PANEL SUPERINSULATION

K. E. Wilkes, J. P Strizak, and F. J. Weaver

J. E. Besser and D. L. Smith

Aladdin Industries, Inc.

Date Published - March 1997

Prepared for the

U. S. Department of Energy

Office of Buildings Energy Research

and

Aladdin Industries, Inc.

Prepared by

OAK RIDGE NATIONAL LABORATORY

Oak Ridge, Tennessee 37831

Managed by

LOCKHEED MARTIN ENERGY RESEARCH CORP.

for the

U.S. DEPARTMENT OF ENERGY

under contract DE-AC05-96OR22464 



\section{TABLE OF CONTENTS}

LIST OF FIGURES $\ldots \ldots \ldots \ldots \ldots \ldots \ldots \ldots \ldots \ldots \ldots \ldots \ldots \ldots \ldots \ldots \ldots$

LIST OF TABLES $\ldots \ldots \ldots \ldots \ldots \ldots \ldots \ldots \ldots \ldots \ldots \ldots \ldots \ldots \ldots \ldots \ldots \ldots$

ABSTRACT $\ldots \ldots \ldots \ldots \ldots \ldots \ldots \ldots \ldots \ldots \ldots \ldots \ldots \ldots \ldots \ldots \ldots \ldots \ldots \ldots$

1. OBJECTIVES OF CRADA $\ldots \ldots \ldots \ldots \ldots \ldots \ldots \ldots \ldots \ldots \ldots \ldots \ldots \ldots \ldots \ldots$

2. BENEFITS OF CRADA TO DOE $\ldots \ldots \ldots \ldots \ldots \ldots \ldots \ldots \ldots \ldots \ldots \ldots \ldots \ldots$

3. TECHNICAL DISCUSSION OF RESULTS $\ldots \ldots \ldots \ldots \ldots \ldots \ldots \ldots \ldots \ldots \ldots \ldots$

3.1 Direct Measurements of Cladding Thermal Conductivity $\ldots \ldots \ldots \ldots \ldots \ldots 2$

3.1.1 Measurement Method . . . . . . . . . . . . . . . . . 2

3.1 .2 Specimens . . . . . . . . . . . . . . . . . . . . . 12

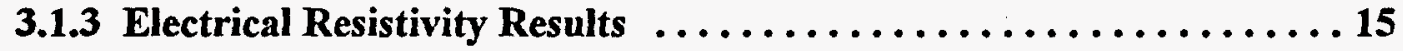

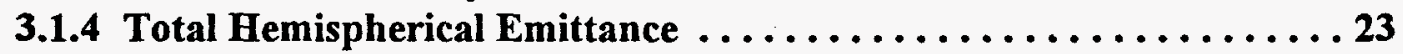

3.1.5 Thermal Conductivity Results .................... 30

3.2 Thermal Measurements on Evacuated Panels $\ldots \ldots \ldots \ldots \ldots \ldots \ldots \ldots \ldots \ldots$

3.2.1 Measurement Method $\ldots \ldots \ldots \ldots \ldots \ldots \ldots \ldots \ldots \ldots \ldots \ldots \ldots \ldots \ldots$

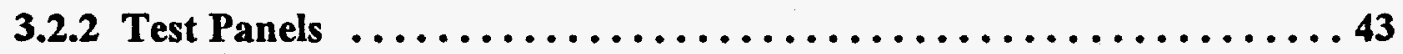

3.2.3 Heat Transmission Results . . . . . . . . . . . . . . . . . 43

3.3 Refrigerator Simulations $\ldots \ldots \ldots \ldots \ldots \ldots \ldots \ldots \ldots \ldots \ldots \ldots \ldots \ldots \ldots$

3.3.1 Energy Savings Due to Evacuated Panels ............... 48

3.3.2 Economic Analysis . . . . . . . . . . . . . . . . . . 51

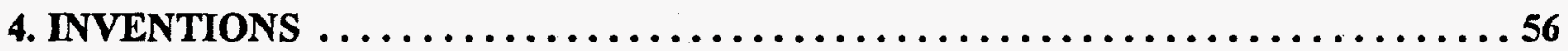

5. COMMERCIALIZATION POSSIBLITIES $\ldots \ldots \ldots \ldots \ldots \ldots \ldots \ldots \ldots$

6. PLANS FOR FUTURE COLLABORATIONS $\ldots \ldots \ldots \ldots \ldots \ldots \ldots \ldots \ldots \ldots \ldots$

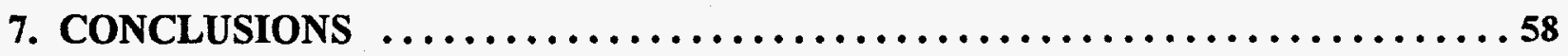

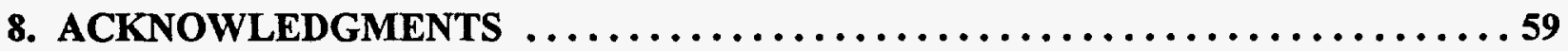

9. REFERENCES ..................................... 59 



\section{LIST OF FIGURES}

1. Schematic of Apparatus for Thermal Conductivity Measurements . . . . . . . . . 3

2. Temperature Profile from Experiment on Specimen 2 at $50^{\circ} \mathrm{C} \ldots \ldots \ldots \ldots \ldots$

3. Temperature Profile from Experiment on Specimen 2 at $100^{\circ} \mathrm{C} \ldots \ldots \ldots \ldots \ldots$

4. Temperature Profile from Experiment on Specimen 2 at $150^{\circ} \mathrm{C} \ldots \ldots \ldots \ldots \ldots \ldots$

5. Temperature Profile from Experiment on Specimen 2 at $200^{\circ} \mathrm{C} \ldots \ldots \ldots \ldots \ldots$

6. Temperature Profile from Experiment on Specimen 2 at $250^{\circ} \mathrm{C} \ldots \ldots \ldots \ldots \ldots$

7. Geometry of Stainless Steel Specimens for Thermal Conductivity Measurements . . . 14

8. Electrical Resistivity of 0.012 inch thick Type 304 Stainless Steel . . . . . . . . . 16

9. Electrical Resistivity of 0.008 inch thick Type 304 Stainless Steel . . . . . . . . . . . 17

10. Electrical Resistivity of 0.0035 inch thick Type 201L Stainless Steel . . . . . . . 18

11. Electrical Resistivity of 0.003 inch thick Type 201 Stainless Steel . . . . . . . . . 19

12. Electrical Resistivity of 0.003 inch thick Type 321 Stainless Steel . . . . . . . . . 20

13. Electrical Resistivity of 0.002 inch thick Type 321 Stainless Steel . . . . . . . . 21

14. Emittance of 0.012 inch thick Type 304 Stainless Steel . . . . . . . . . . . . 24

15. Emittance of 0.008 inch thick Type 304 Stainless Steel $\ldots \ldots \ldots \ldots \ldots \ldots \ldots$

16. Emittance of 0.0035 inch thick Type 201L Stainless Steel . . . . . . . . . . . 26

17. Emittance of 0.003 inch thick Type 201 Stainless Steel $\ldots \ldots \ldots \ldots \ldots \ldots \ldots \ldots$

18. Emittance of 0.003 inch thick Type 321 Stainless Steel $\ldots \ldots \ldots \ldots \ldots \ldots \ldots$

19. Emittance of 0.002 inch thick Type 321 Stainless Steel . . . . . . . . . . . . 29

20. Comparison of Measured Total Hemispherical Emittance with Total Normal Emittance

Calculated from Electromagnetic Theory . . . . . . . . . . . . . . . 31

21. Thermal Conductivity of 0.012 inch thick Type 304 Stainless Steel . . . . . . . . 32

22. Thermal Conductivity of 0.008 inch thick Type 304 Stainless Steel . . . . . . . . . 33

23. Thermal Conductivity of 0.0035 inch thick Type $201 \mathrm{~L}$ Stainless Steel $\ldots \ldots \ldots \ldots$

24. Thermal Conductivity of 0.003 inch thick Type 201 Stainless Steel . . . . . . . . 35

25. Thermal Conductivity of 0.003 inch thick Type 321 Stainless Steel . . . . . . . . . . 36

26. Thermal Conductivity of 0.002 inch thick Type 321 Stainless Steel . . . . . . . . . 37

27. Arrangement of Heat Flux Meter Apparatus for Tests on Evacuated Panels . . . . . 41

28. Arrangement of Heat Flow Meter Apparatus for Measurements on Evacuated Panels (top

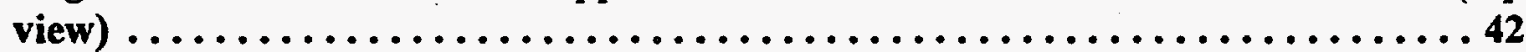

29. Calculated Annual Energy Usage for Refrigerator with 0.5 Inch Thick Evacuated Panels

30. Calculated Annual Energy Usage for Refrigerator with 1 Inch Thick Evacuated Panels

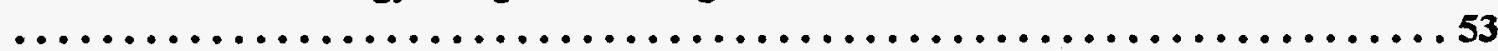

31. Calculated Lifetime Value of Energy Savings for Refrigerator with 0.5 Inch Thick Evacuated Panels . ................................ 54

32. Calculated Lifetime Value of Energy Savings for Refrigerator with 1 Inch Thick Evacuated Panels . . . . . . . . . . . . . . . . . . . . . . . . . 55

33. Cost-benefit Relationship for One-Inch Thick Evacuated Panels with Stainless Steel Cladding and R-50 per Inch Filler Applied to Typical Refrigerator . . . . . . 57 



\section{LIST OF TABLES}

1. Typical Composition of Stainless Steels ......................... 13

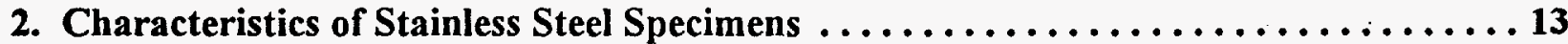

3. Location of Thermocouples Along Length of Specimens ................ 15

4. Deviation (percent) between Measured Electrical Resistivity and CINDAS Recommended

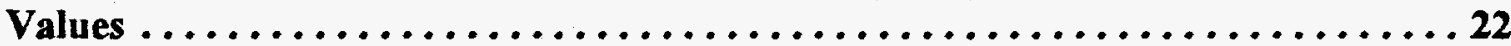

5. Variation of Electrical Resistivity along Specimen Length $\ldots \ldots \ldots \ldots \ldots \ldots \ldots 22$

6. Deviation (percent) between Regression Curve for Measured Thermal Conductivity and

CINDAS Recommended Values ............................39

7. Room Temperature $\left(7^{\circ} \mathrm{F}\right)$ Thermal Conductivity from Direct Measurements . .... 39

8. Characteristics of Evacuated Panels . .......................... 44

9. Center-of-Panel and Filler Thermal Resistivities for Evacuated Panels .......... 44

10. Center-of-Panel and Overall Panel Thermal Resistivities for Evacuated Panels . . . . 47

11. Results of Computer Program Simultaneous Estimation of Cladding Thermal Conductivity, Filler Resistivity and Overall Panel Resistivity ............47

12. Characteristics of Refrigerator Used for Simulations of Energy Savings with Evacuated Panels ........................................ 49

13. Changes Made to EPA Baseline Refrigerator Characteristics $\ldots \ldots \ldots \ldots \ldots \ldots . \ldots 0$ 


\title{
DEVELOPMENT OF METAL-CLAD FILLED EVACUATED PANEL SUPERINSULATION
}

\author{
K. E. Wilkes, J. P. Strizak, F. J. Weaver, J. E. Besser, and D. L. Smith*
}

\begin{abstract}
This Cooperative Research and Development Agreement (CRADA) was between Aladdin Industries, Inc. and Lockheed Martin Energy Research Corp. The purpose of the CRADA was to determine the thermal performance of various metal claddings used to encapsulate Filled Evacuated Panel (FEP) superinsulation and to optimize the cost versus thermal performance of the claddings. A FEP superinsulation is a new type of superinsulation with the potential for saving large amounts of energy in buildings, building equipment, transportation (refrigerated railcars and trucks), industrial applications, etc. The major disadvantage of metal claddings for FEPs is the heat loss through the cladding caused by the high thermal conductivity of most metals. In smaller FEPs, this heat loss can degrade the overall performance of the FEP by factors of two or more as compared with polymer-clad FEPs. On the other hand, metal claddings are essentially impermeable to ambient air, whereas polymer claddings are not. Thus, the longevity and reliability of metal-clad FEPs are much superior to polymer-clad FEPs. In addition, because of the very low vapor pressure of metals as compared to polymers, metal-clad FEPs can achieve and operate at lower internal pressures. These lower pressures allow use of less expensive and/or higher performance filler materials.
\end{abstract}

\section{OBJECTIVES OF CRADA}

The objective of the CRADA was to determine the effects of metallic claddings on the overall thermal performance of evacuated panel superinsulation, including the effects of different thicknesses and types of metal claddings. The impact of cladding design on energy savings due to application of evacuated panel superinsulations to refrigerators was also to be estimated.

\section{BENEFITS OF CRADA TO DOE}

A major part of the Building Materials Program, which is funded by the DOE Office of Buildings Energy Research, is the development of evacuated panels with higher thermal resistance, lower costs, and longer lifetimes. The procedures and technology learned in evaluating the heat losses due to conduction through stainless steel claddings will be of direct benefit to the R\&D efforts of the Building Materials Program. ORNL will continue to develop the technology

'K. E. Wilkes, J. P. Strizak, and F. J. Weaver, Metals \& Ceramics Division, Oak Ridge National Laboratory; J. E. Besser and D. L. Smith, Aladdin Industries, Inc. 
to optimize the cost-benefit relationships for evacuated panels for applications in both appliances and in the envelopes of buildings.

\section{TECHNICAL DISCUSSION OF RESULTS}

Results from this CRADA are organized into three sections. In the first section, results are given of direct measurements of the thermal conductivity of several types and thicknesses of stainless steel foils that were being considered for use in evacuated panel superinsulations. These measurements were undertaken to obtain data on the foils in the actual thicknesses and heat treatments that are being used in superinsulations. The second section gives results on measurements of the thermal resistance of several evacuated panels that were fabricated using different types and thicknesses of steel. The final section gives the results of simulations of the energy performance of refrigerators that would incorporate evacuated panels into their walls and doors. Energy savings are given for different thicknesses of stainless steel vacuum jackets used in conjunction with filler materials with different thermal resistances.

\subsection{Direct Measurements of Cladding Thermal Conductivity}

\subsubsection{Measurement Method}

The thermal conductivities of selected stainless steel foils were measured using a direct electrical heating method. The apparatus used for these measurements was an adaptation of an ASTM C 835 apparatus normally used for measurement of the total hemispherical emittance of metals. The apparatus is shown schematically in Figure 1.[1] A specimen in the shape of a dogbone was clamped between two water-cooled electrodes inside an evacuated chamber with water-cooled walls. The specimen was heated by passage of a direct electrical current to temperatures ranging from room temperature to $500^{\circ} \mathrm{C}$. Eight platinum versus platinum- 10 percent rhodium thermocouples, made from 0.003 in. diameter wire, were spot welded to the specimen at selected positions along its length. The two elements were welded separately to the specimen. In addition to providing a measurement of the temperature profile along the specimen, the platinum-10 percent rhodium thermoelements were used to measure the voltage drop along the specimen. The thermal conductivity was inferred from the measured temperature profile. 


\section{Thermocouples and Voltage Taps}

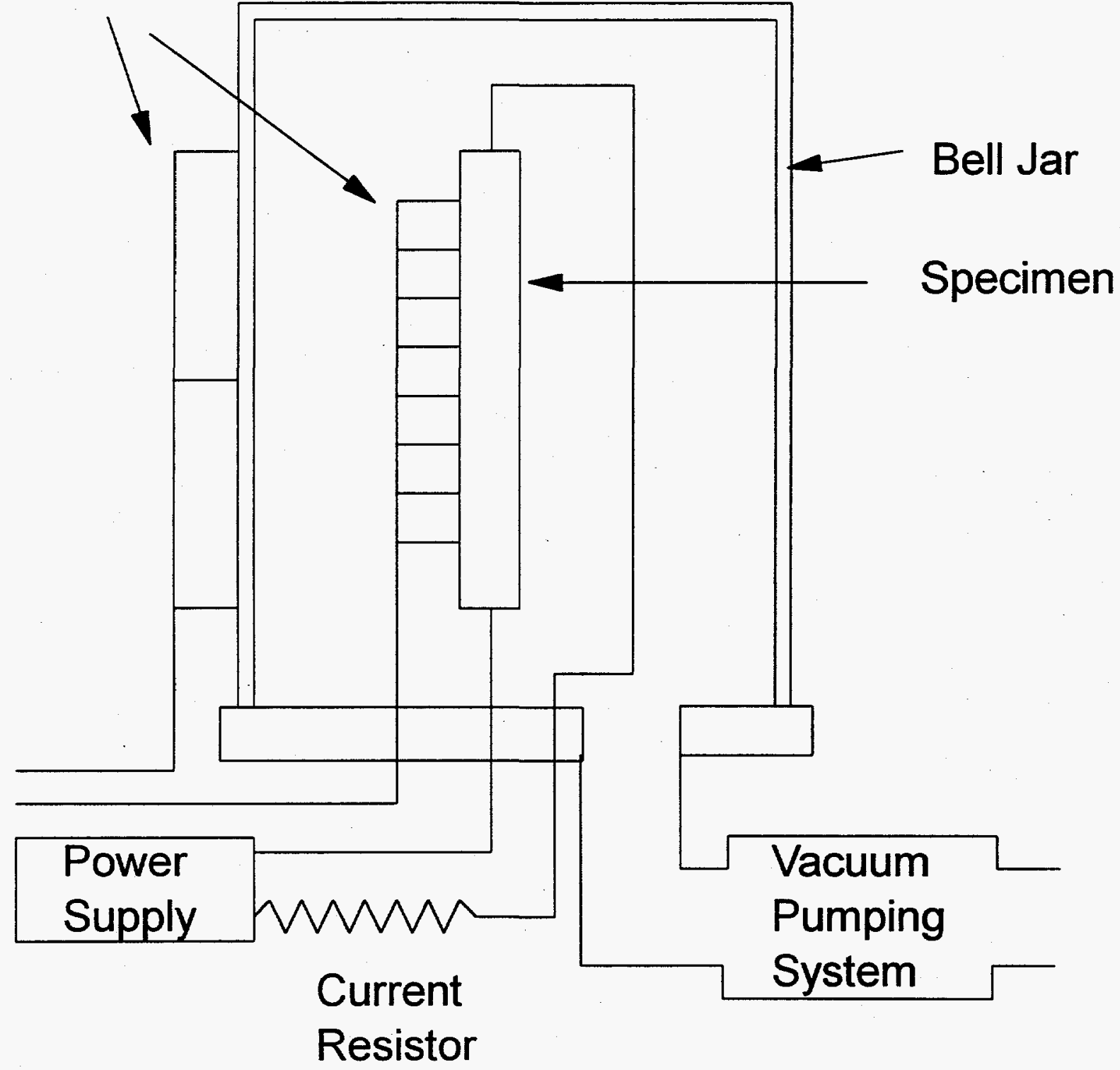

Figure 1. Schematic of Apparatus for Thermal Conductivity Measurements 
This measurement gives the thermal conductivity in the direction parallel to the specimen surface. This is the direction of interest for applications as vacuum claddings for superinsulation, since the heat flow around the edges of vacuum superinsulations is in the plane of the metal.

Direct electrical heating methods have been used for nearly 100 years for measurement of the thermal conductivity of metals.[2,3] If the metal specimen has a large cross sectional area so that heat losses from the surfaces are negligible compared with conduction along the specimen, then the temperature profile will be a parabola. If this is the case, the thermal conductivity can be calculated from an algebraic equation using temperatures measured at the midpoint and at one other location (assuming symmetrical cooling of the ends). When heat losses from the surface become significant, the temperature profile is more complex and analysis of the data is more difficult. Figures 2 through 6 show measured temperature profiles for one of the specimens at a sequence of increasing temperature levels. [Note: In section 3.1, a mixed set of units is used. Inch units are used for specimen dimensions, while the SI units customarily used with C 835 are used for temperatures and thermophysical properties.] The shape of the temperature profile at the lowest temperature is approximately parabolic, but as the temperature is increased the profile becomes flatter in the middle and steeper at the ends. At very high temperatures, the heat generated by the electrical current is nearly equal to that radiated from the surface, heat flows by conduction are minimal, and the temperature profile is very flat, except at the very ends of the specimen.

An energy balance on a differential length of a thin specimen yields the following differential equation:

$$
\frac{I^{2} \rho}{A}-P \in \sigma\left(T^{4}-T_{0}^{4}\right)+A \frac{d}{d x}\left(k \frac{d T}{d x}\right)=0
$$

where $I=$ current

$\rho=$ electrical resistivity

$A=$ cross sectional area of specimen

$\mathrm{P}=$ perimeter of specimen

$\epsilon=$ total hemispherical emittance 


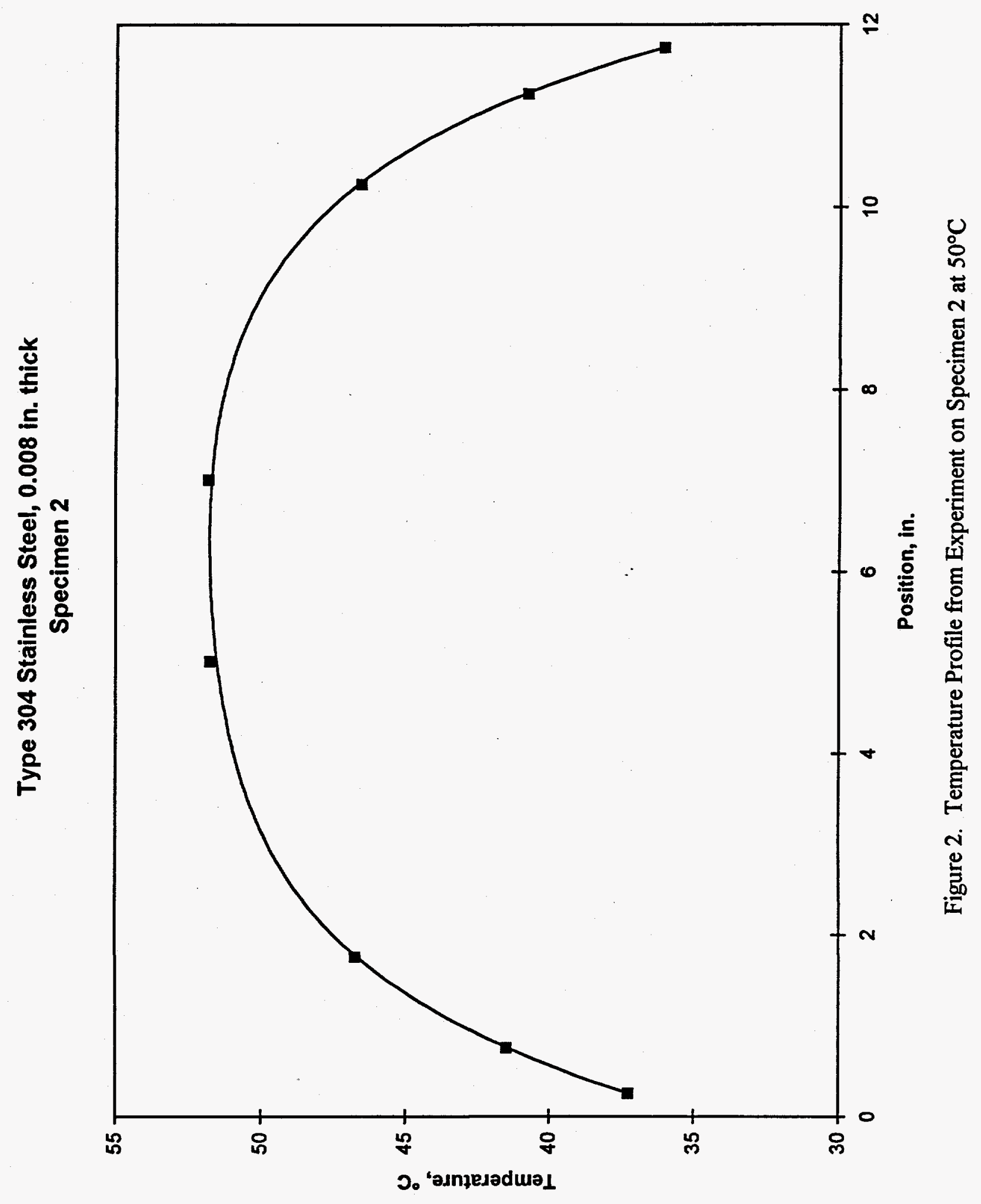


Type 304 Stainless Steel, 0.008 in. thick

Specimen 2

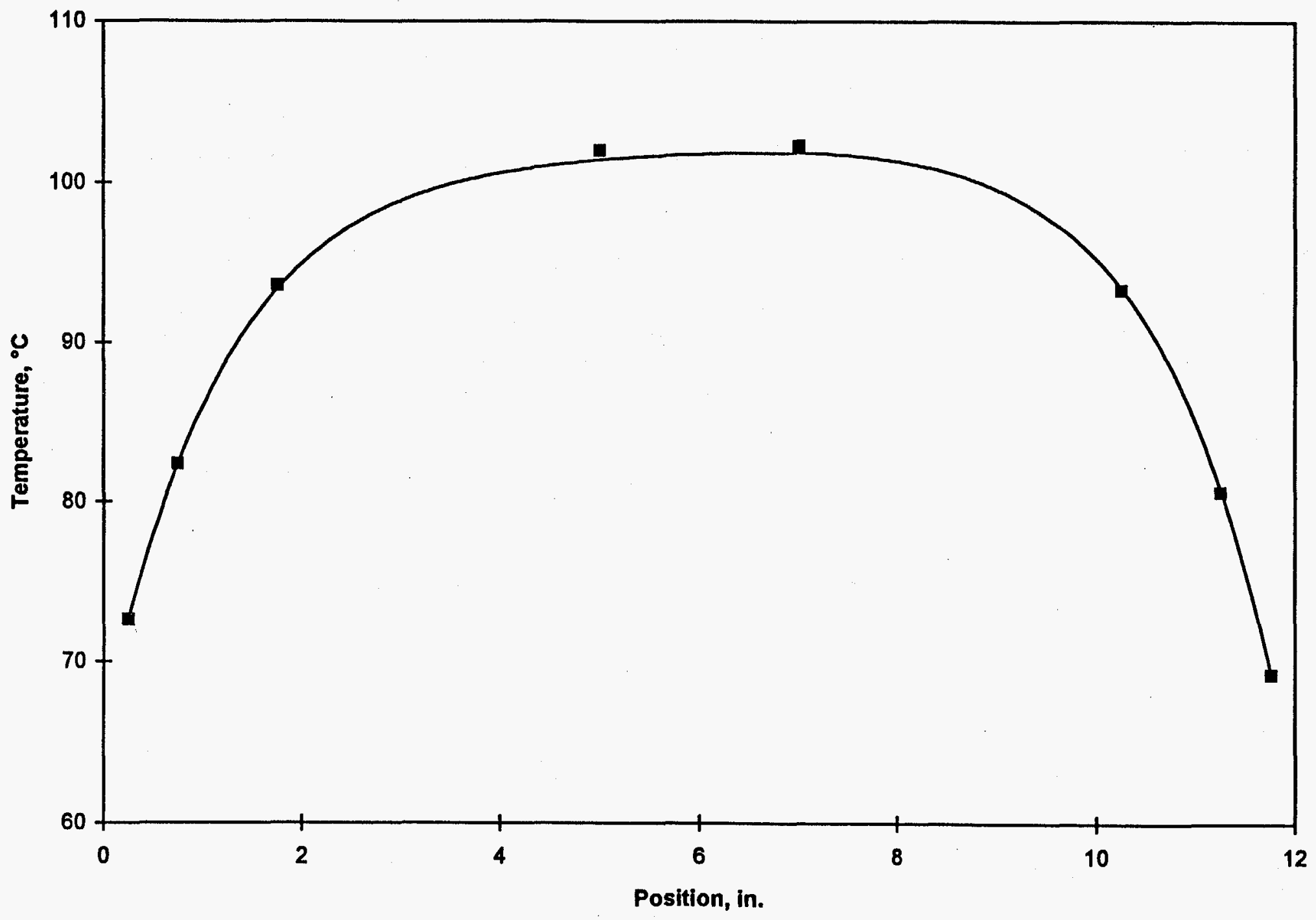

a

Figure 3. Temperature Profile from Experiment on Specimen 2 at $100^{\circ} \mathrm{C}$ 
Type 304 Stainless Steel, 0.008 in. thick

Specimen 2

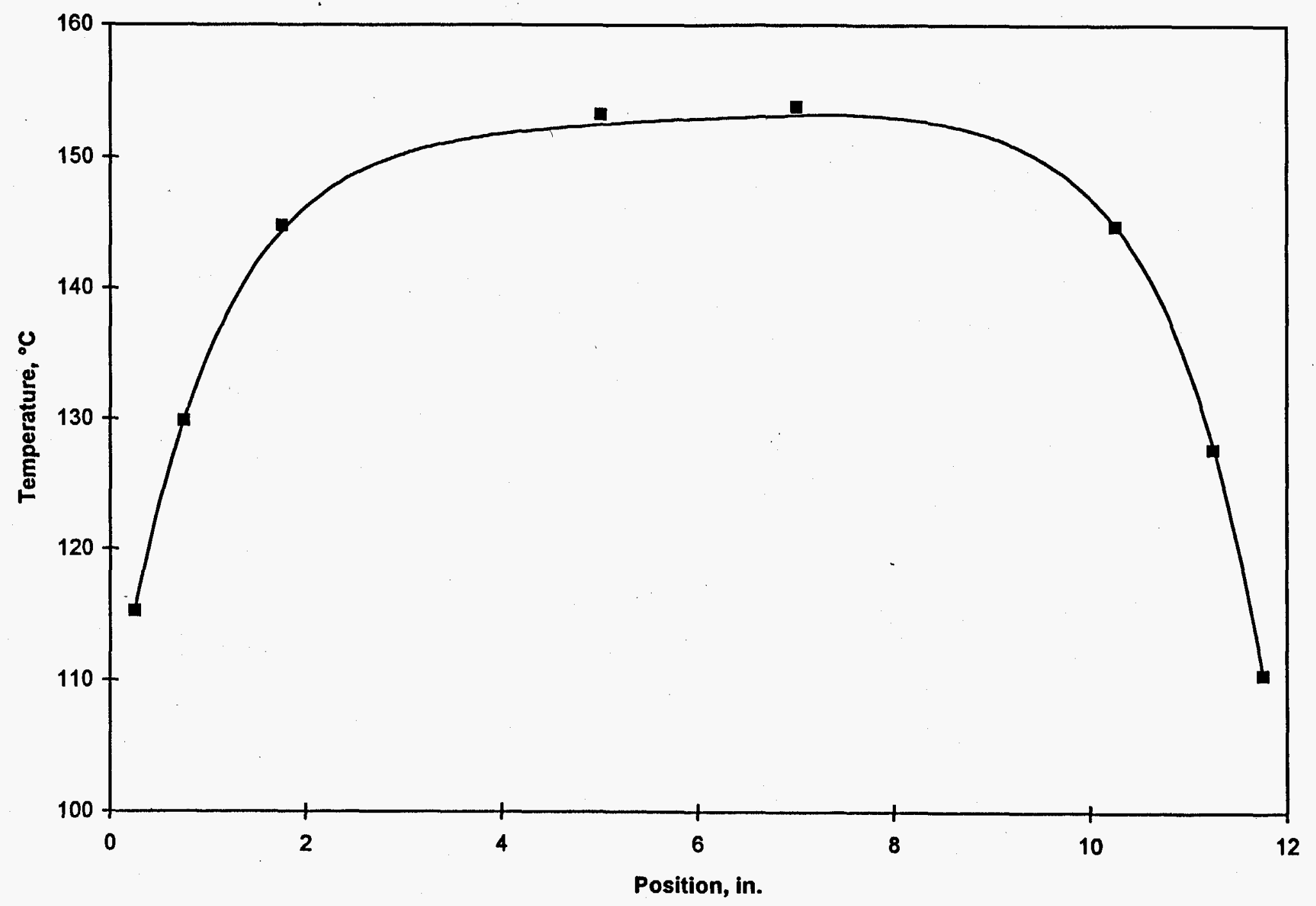

Figure 4. Temperature Profile from Experiment on Specimen 2 at $150^{\circ} \mathrm{C}$ 


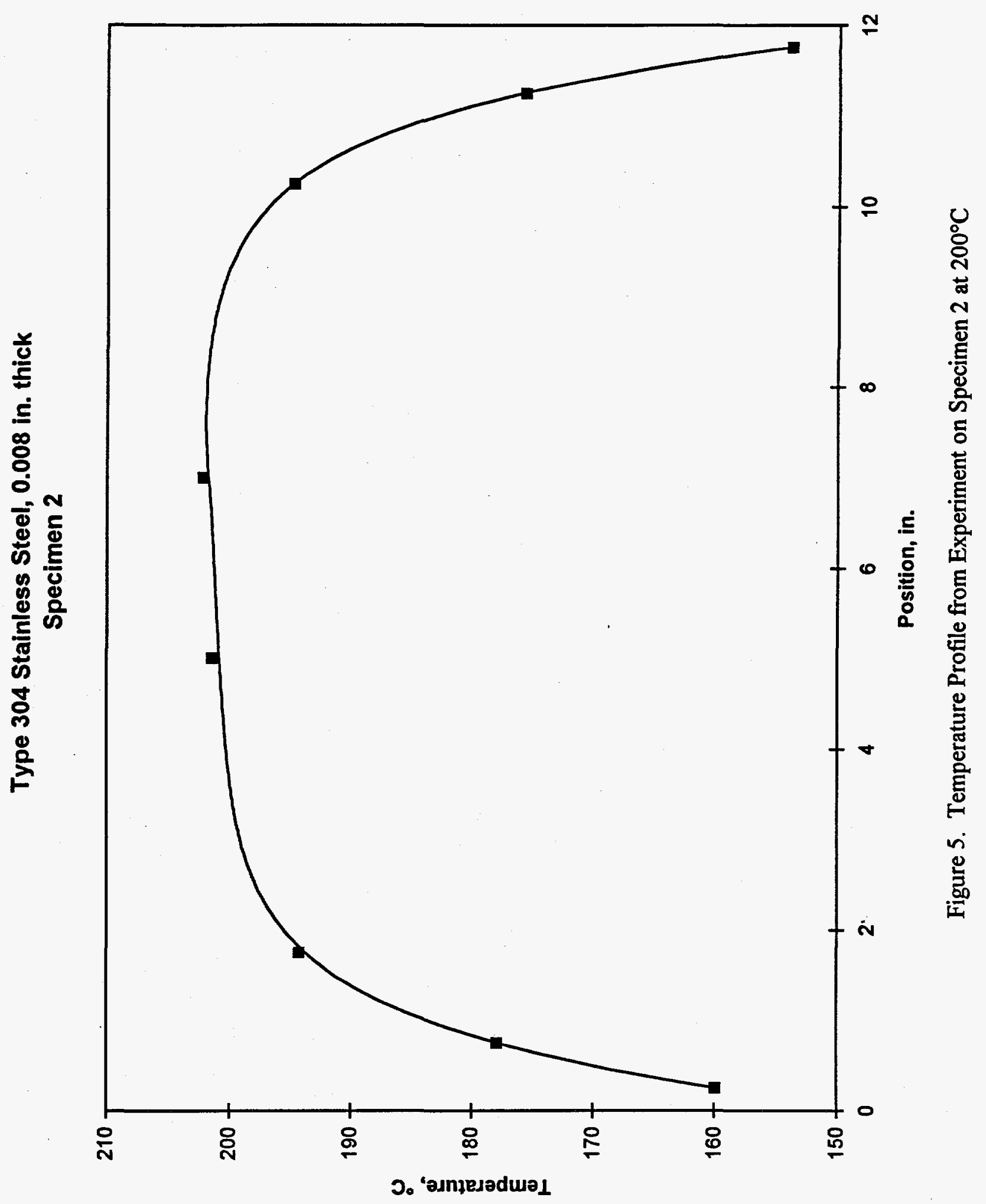




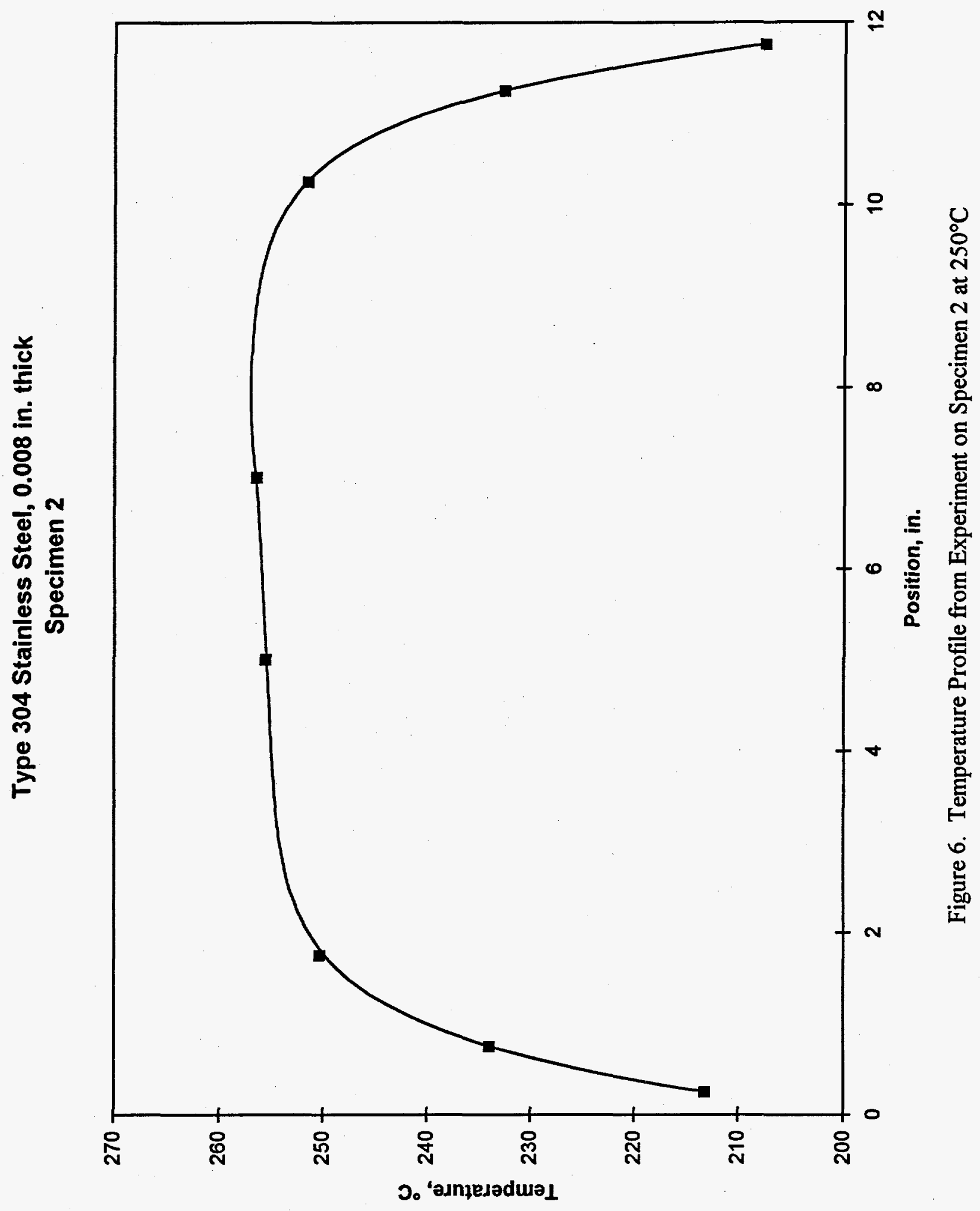


$\sigma=$ Stefan-Boltzmann constant

$\mathrm{T}=$ absolute temperature of specimen at position $\mathrm{x}$

$T_{0}=$ absolute temperature of specimen surroundings

$\mathbf{x}=$ position on specimen

$k=$ thermal conductivity

The first term in Equation 1 represents the Joulean heat generated by passage of the electrical current, the second term represents the heat lost by radiation, and the third term represents the heat conducted along the length of the specimen. Equation 1 assumes that the temperature of the specimen varies only in the length direction and not across the width or through the thickness. This assumption is justified for thin foils such as the ones used in the present study.

Equation 1 is highly nonlinear because of the $\mathrm{T}^{4}$ radiation term and also because the three thermophysical properties (electrical resistivity, emittance, and thermal conductivity) may vary significantly with temperature. Because of the nonlinearities, an exact analytical solution to extract the thermal conductivity from measured quantities is generally not possible. Past studies using direct heating methods have resorted to various approximations to obtain thermal conductivity values; these are summarized by Flynn [4] and by Taylor [5]. For this project, we used computer methods to deduce the thermal conductivity from numerical solutions of Equation 1 without resorting to any approximations.

Reduction of experimental data consisted of three steps. In the first step, the electrical resistivity was obtained from the voltage drop, $\Delta \mathrm{V}$, between the two thermocouples that span the center 2 in. section of the specimen, using the following equation:

$$
\rho=\frac{\Delta V}{\Delta L} \frac{A}{I}
$$

where $\Delta \mathrm{L}$ is the distance between the two thermocouples. The temperature assigned to the resistivity value is the average of the readings of the two center thermocouples. Since the center 2 in. section was usually very isothermal, the temperature that applies to the resistivity value is well defined. The resistivity values were then plotted versus temperature and the data were fitted 
by the method of least squares to obtain a quadratic equation of the form:

$$
\rho=a+b \cdot T+c \cdot T^{2}
$$

where $\mathrm{a}, \mathrm{b}$, and $\mathrm{c}$ are constants obtained from the fitting procedure. As will be seen, this equation gives very good representations of the data.

In the second step of data analysis, the total hemispherical emittance was calculated from the voltage drop $(\Delta V)$ between the two thermocouples that span the center 2 in. section and the average of the temperature readings of these two thermocouples, using the following equation

$$
\epsilon=\frac{\Delta \mathrm{V} \cdot \mathrm{I}}{\mathrm{P} \Delta \mathrm{x} \sigma\left(\mathrm{T}^{4}-\mathrm{T}_{0}^{4}\right)}
$$

where again $\Delta \mathrm{x}$ is the distance between the two thermocouples. This equation assumes that the heat generated in the center section is exactly balanced by heat radiated from the surface of the specimen. This would be exact if there were absolutely no heat conduction along the length of the specimen. In reality, there is a small amount of conduction since the temperature profile is not exactly flat even over the center 2 in. section of the specimen. A correction was made to Equation 4 by fitting a cubic spline [6] to the temperature profile and calculating the conduction heat transfer at the ends of the 2 in. section. For these calculations, thermal conductivity values from the literature [7] for Type 304L stainless steel were used. Use of literature values for the thermal conductivity was justified since the correction was never greater than 3 percent, and was usually much less. The emittance versus temperature values were also fitted to an equation of the quadratic form. As will be seen, the data fit this form of equation very well.

In the third step of the data analysis, a special purpose finite difference computer program was written and used to solve for the thermal conductivity. The inputs to the computer program consisted of the geometry of the specimen (width, thickness, distance between each of the thermocouples), temperatures read by the thermocouples nearest the water-cooled ends, the electrical current, and the equations for electrical resistivity and emittance versus temperature. With this input, the computer program would assume a value for the thermal conductivity and then predict the temperatures at the locations of the other thermocouples. A systematic search 
was used to find the value of the thermal conductivity that resulted in the least squares difference between the calculated and measured temperature profiles. Figures 2 through 6 show comparisons between the calculated (curves) and measured (symbols) temperature profiles. The temperature assigned to the thermal conductivity value was the average of the low and high temperatures along the specimen.

\subsubsection{Specimens}

Specimens of four stainless steel alloys (AISI Types 201, 201L, 304, and 321) were provided by Aladdin Industries. Nominal chemical compositions of the alloys are given in Table 1.[8] The major alloying elements are chromium, which imparts oxidation resistance, and nickel, which stabilizes the alloy in the austenitic phase. The basic alloy in the austenitic stainless steel family is Type 302, which contains about 18 percent chromium and 8 percent nickel (hence, 18-8 stainless steels). In Type 201, manganese and nitrogen partly replace the nickel. Type 201L is similar but has lower carbon content to provide improved corrosion resistance in welded structures. Type 304 is similar to Type 302, but has a lower carbon content also for better corrosion resistance in welded structures. Type 304L has an even lower carbon content. In Type 321 , titanium is added to prevent chromium carbide precipitation and hence improve the resistance to intergranular corrosion.

Aladdin prepared specimens in the geometry shown in Figure 7. The specimens were in the shape of a dogbone with a 12 inch long section having a nearly uniform width of 0.5 inches. Specimen thicknesses ranged from 0.002 to 0.012 inches. The specimens and their measured thicknesses are identified in Table 2. Eight platinum versus platinum-10 percent rhodium thermocouples were spot welded to the uniform-width section of the specimens at the locations given in Table 3. Two of the thermocouples spanned the central 2 in. long section (locations of 5.0 and 7.0 inches). Thermocouples were placed within $0.25 \mathrm{in}$. of the ends of the uniform-width section, and the others were placed at intermediate locations to attempt to capture the shape of the temperature profile. 
Table 1. Typical Composition of Stainless Steels

\begin{tabular}{|c|c|c|c|c|c|c|c|c|}
\hline $\begin{array}{c}\text { AISI } \\
\text { Type }\end{array}$ & $\mathrm{C}$ & $\mathrm{Mn}$ & $\mathrm{Si}$ & $\mathrm{Cr}$ & $\mathrm{Ni}$ & $\mathrm{P}$ & $\mathrm{S}$ & Others \\
\hline 302 & 0.15 & 2.00 & 1.00 & $17.0-19.0$ & $8.0-10.0$ & 0.045 & 0.03 & \\
\hline 201 & 0.15 & $5.5-7.5$ & 1.00 & $16.0-18.0$ & $3.5-5.5$ & 0.06 & 0.03 & $0.25 \mathrm{~N}$ \\
\hline 304 & 0.08 & 2.00 & 1.00 & $18.0-20.0$ & $8.0-10.5$ & 0.045 & 0.03 & \\
\hline $304 \mathrm{~L}$ & 0.03 & 2.00 & 1.00 & $18.0-20.0$ & $8.0-12.0$ & 0.045 & 0.03 & \\
\hline 321 & 0.08 & 2.00 & 1.00 & $17.0-19.0$ & $9.0-12.0$ & 0.045 & 0.03 & $\begin{array}{c}5 \times \% \mathrm{C} \\
\operatorname{min~Ti}\end{array}$ \\
\hline
\end{tabular}

Note: compositions are given in weight percent.

Source: Metals Handbook [8]

Table 2. Characteristics of Stainless Steel Specimens

\begin{tabular}{|c|c|c|}
\hline Specimen & Type & Thickness, inches \\
\hline 1 & 304 & 0.01215 \\
\hline 2 & 304 & 0.00823 \\
\hline 3 & $201 \mathrm{~L}$ & 0.00349 \\
\hline 4 & 201 & 0.00305 \\
\hline 5 & 321 & 0.00311 \\
\hline 6 & 321 & 0.00208 \\
\hline
\end{tabular}




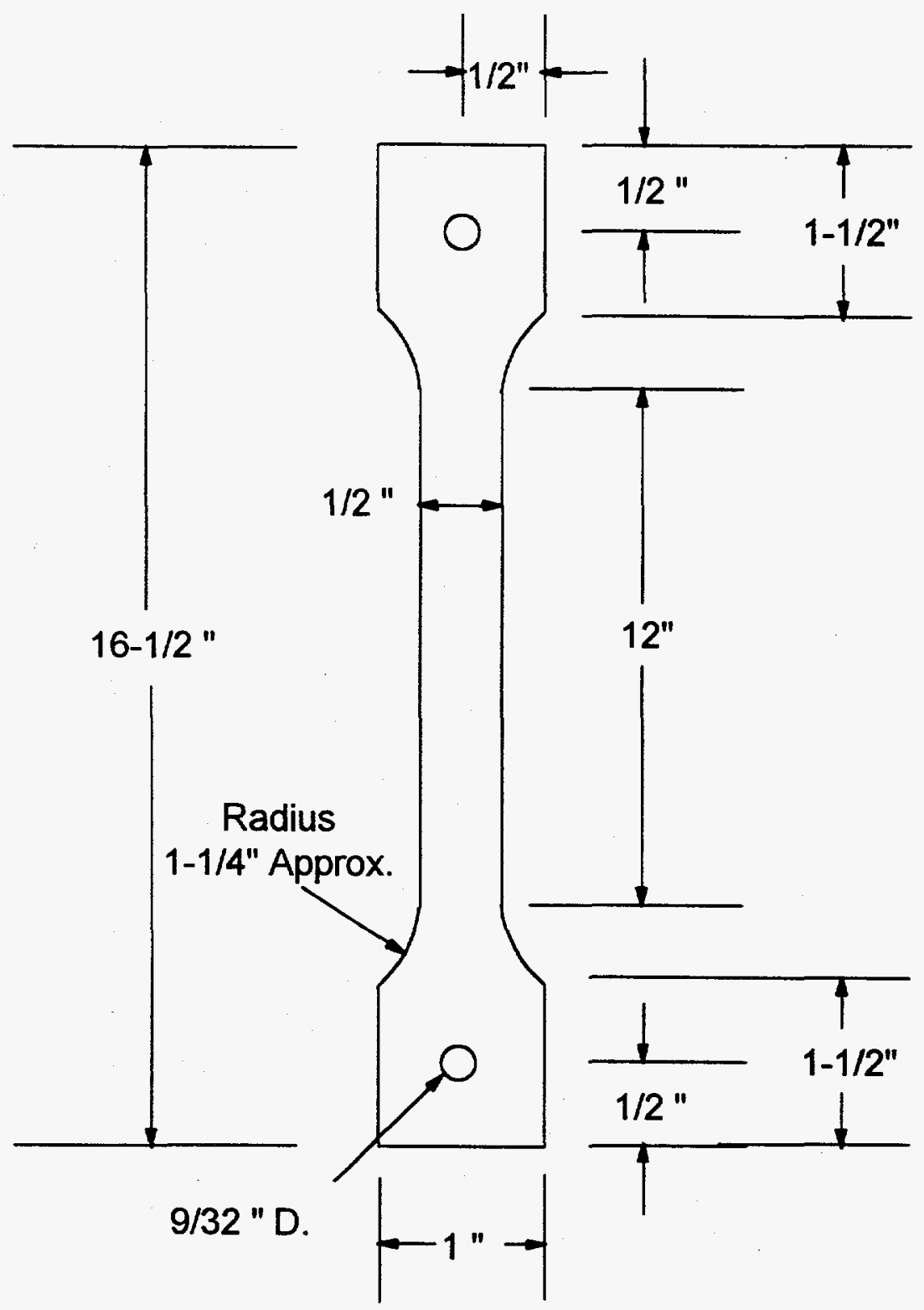

Note: not to scale

Figure 7. Geometry of Stainless Steel Specimens for Thermal Conductivity Measurements 
Table 3. Location of Thermocouples Along Length of Specimens

\begin{tabular}{|c|c|c|c|c|c|}
\hline Specimen 1 & Specimen 2 & Specimen 3 & Specimen 4 & Specimen 5 & Specimen 6 \\
\hline 0.5 & 0.25 & 0.25 & 0.25 & 0.25 & 0.25 \\
\hline 2.0 & 0.75 & 0.5 & 0.5 & 0.5 & 0.75 \\
\hline 3.5 & 1.75 & 1.0 & 1.0 & 1.0 & 1.75 \\
\hline 5.0 & 5.0 & 5.0 & 5.0 & 5.0 & 5.0 \\
\hline 7.0 & 7.0 & 7.0 & 7.0 & 7.0 & 7.0 \\
\hline 8.5 & 10.25 & 11.0 & 11.0 & 11.0 & 10.25 \\
\hline 10.0 & 11.25 & 11.5 & 11.5 & 11.5 & 11.25 \\
\hline 11.5 & 11.75 & 11.75 & 11.75 & 11.75 & 11.75 \\
\hline
\end{tabular}

Note: locations are distances (in inches) from the top of the 12 inch long uniform width section.

\subsubsection{Electrical Resistivity Results}

Results of the electrical resistivity measurements from the central 2 in. section of the specimens are given in Figures 8 through 13. The lines through the data points were calculated from the least squares fit, and the equations and coefficients of determination $\left(r^{2}\right)$ are also given in the figures. In all cases, the coefficients of determination were greater than 0.9998 , indicating that the quadratic equation gives the correct variation of resistivity with temperature. Data were taken as the specimen was heated up to $500^{\circ} \mathrm{C}$ (called Run 1), and then as the specimen was cooled back to room temperature (called Run 2). No evidence of hysteresis was observed, indicating that the microstructural aspects of the specimens that affect the electrical resistivity were stable at least up to $500^{\circ} \mathrm{C}$ over the duration of the test. Table 4 compares the present results with the values recommended by CINDAS**.[9,10] The present values for Specimens 1 and 2, which were made of Type 304, are within \pm 2 percent of the CINDAS values. The data for Specimen 3, which was made of Type 201L, are within 0.5 percent of the CINDAS values, while

"*CINDAS is the Center for Information and Numerical Data Analysis and Synthesis at Purdue University, and is recognized as an international authority on thermophysical properties. 
Type 304 Stainless Steel, 0.012 in. thick

Specimen 1

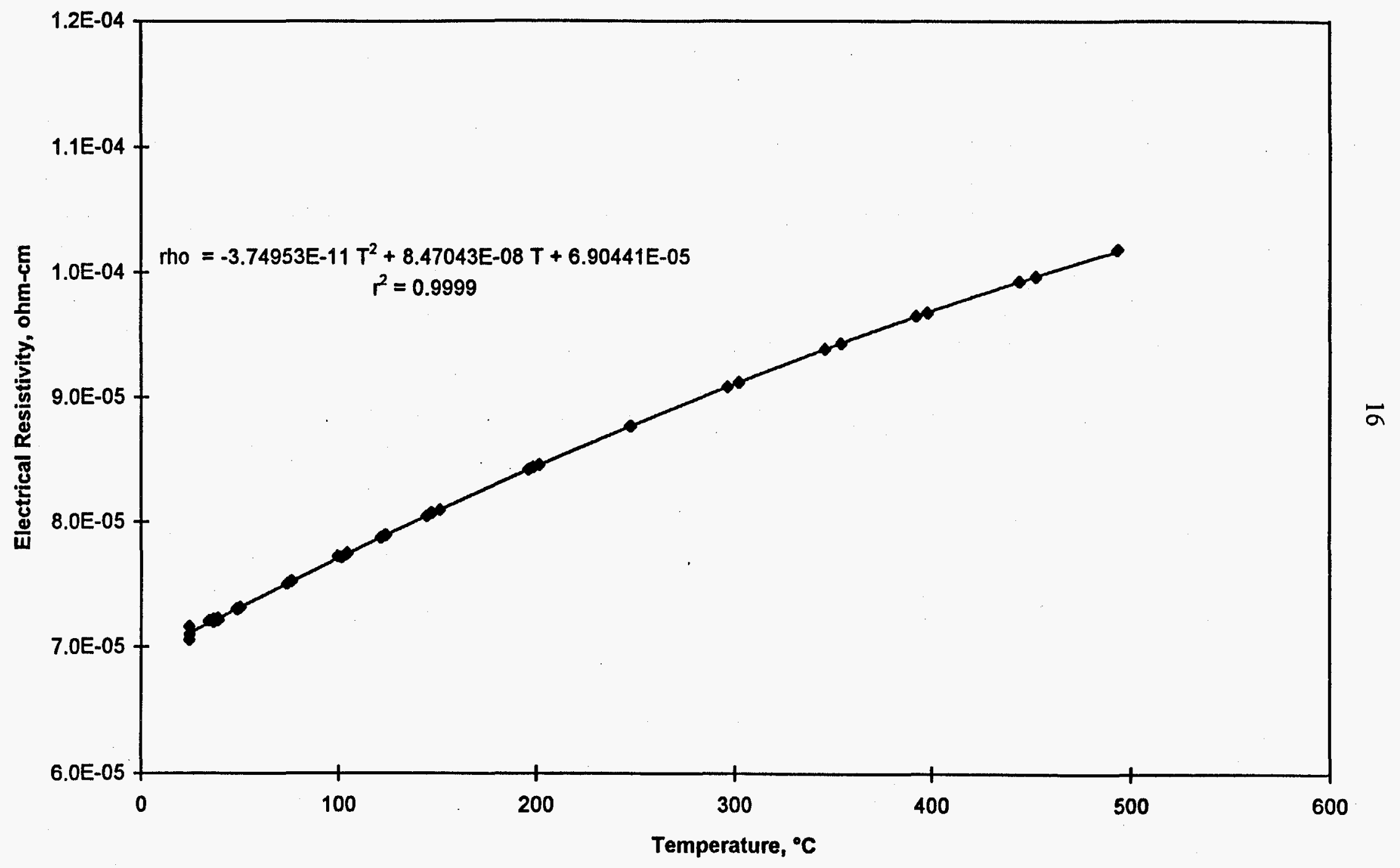

Figure 8. Electrical Resistivity of 0.012 inch thick Type 304 Stainless Steel 


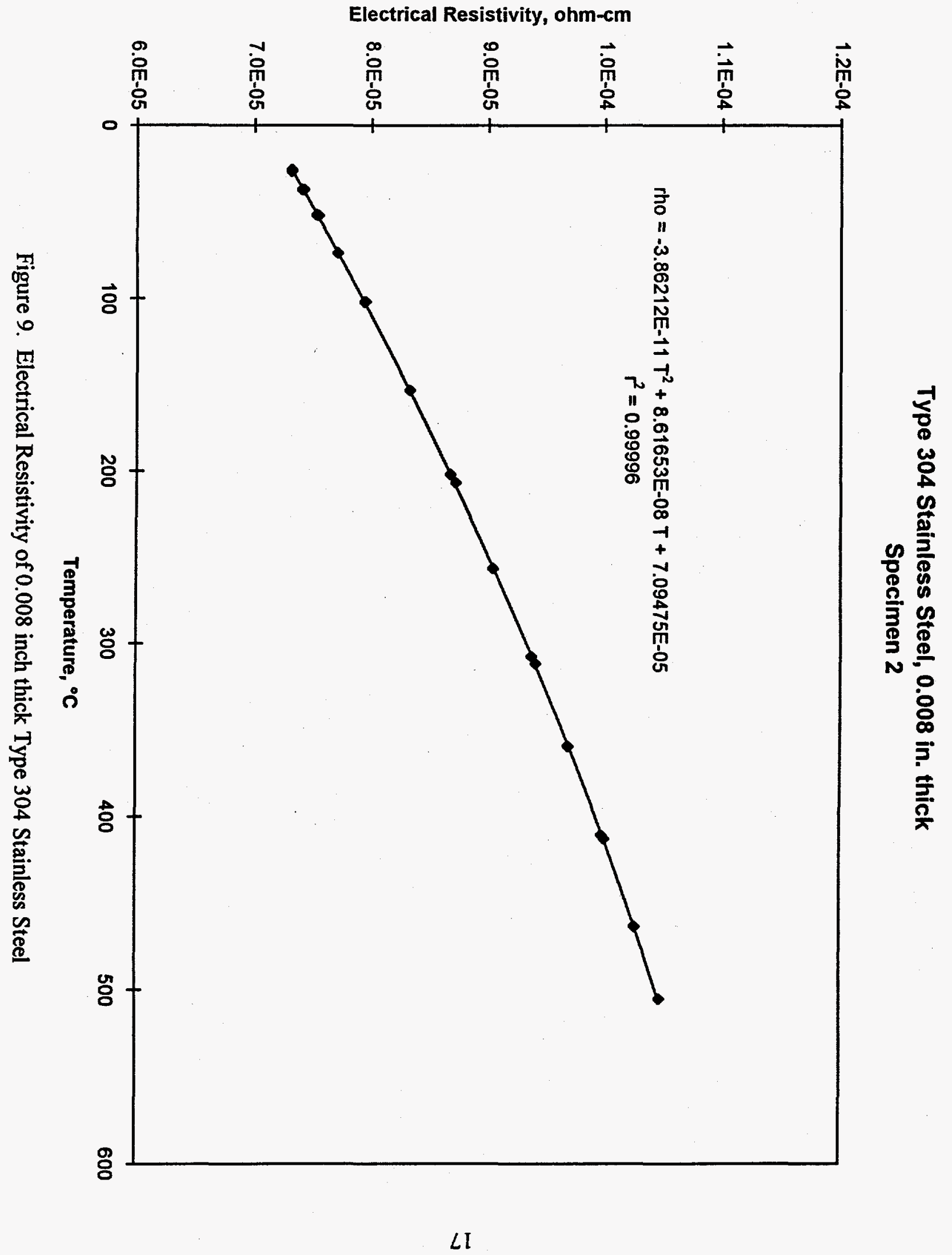


Type 201L Stainless Steel, 0.0035 in. thick

Specimen 3

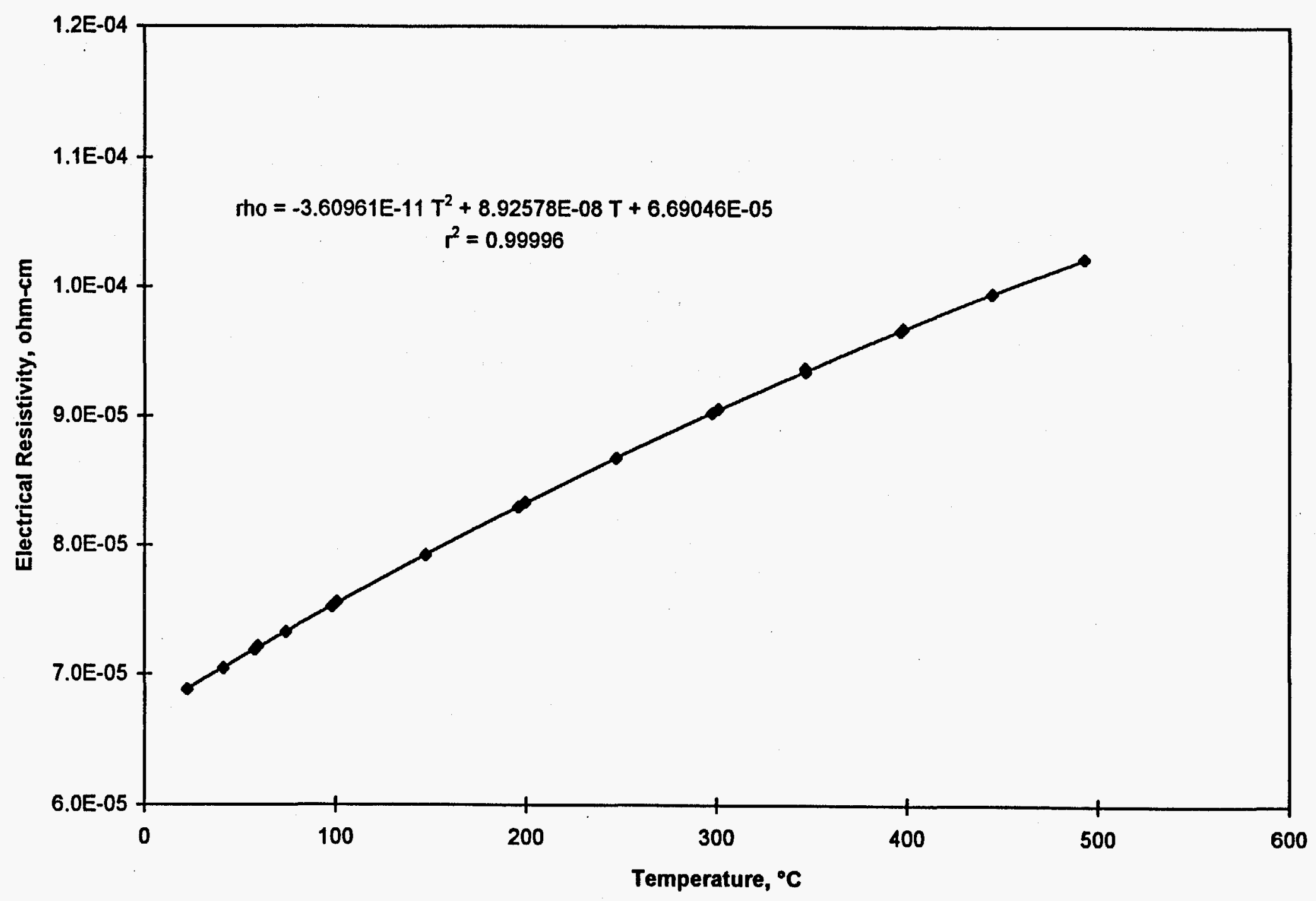

Figure 10. Electrical Resistivity of 0.0035 inch thick Type 201L Stainless Steel 


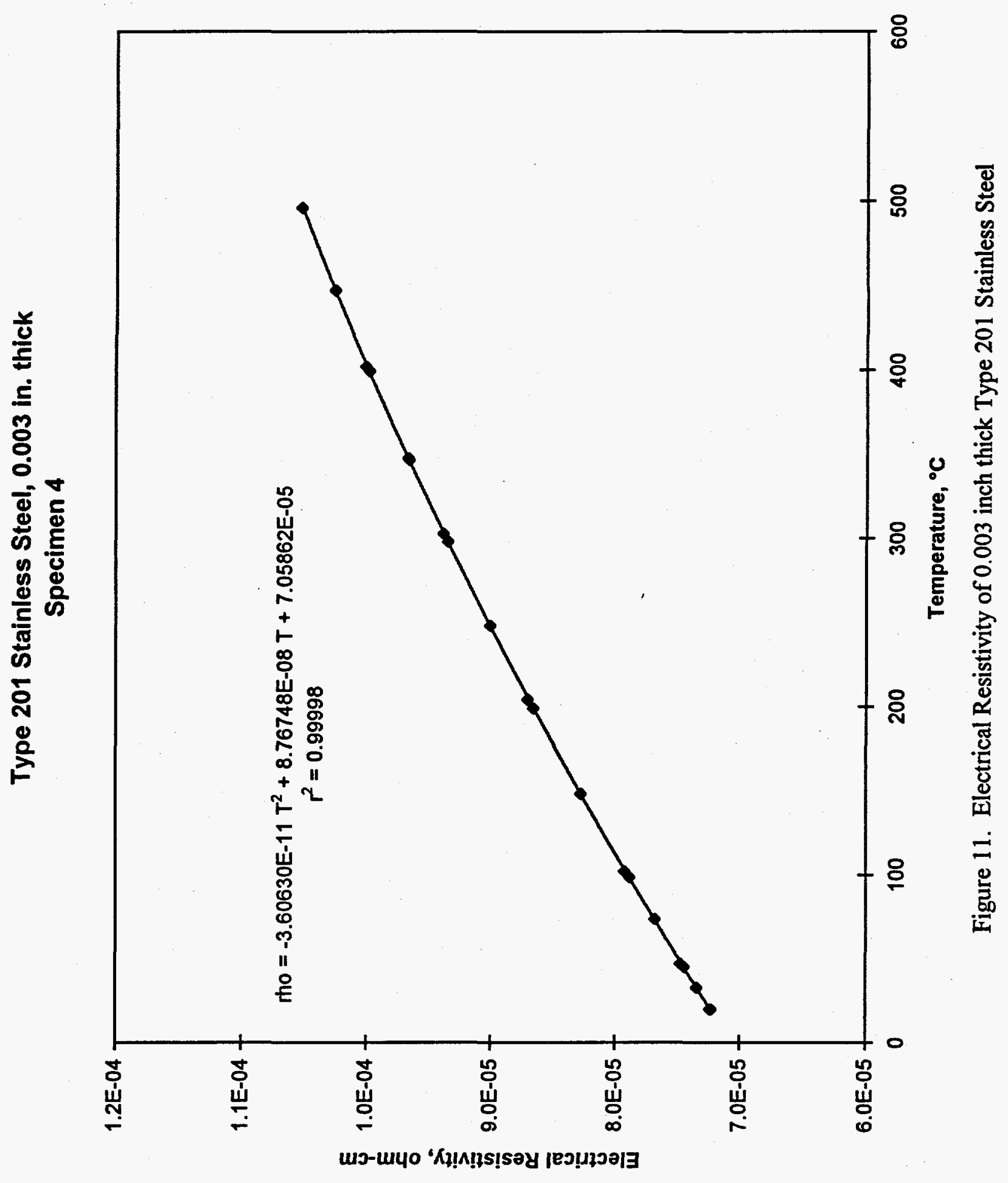




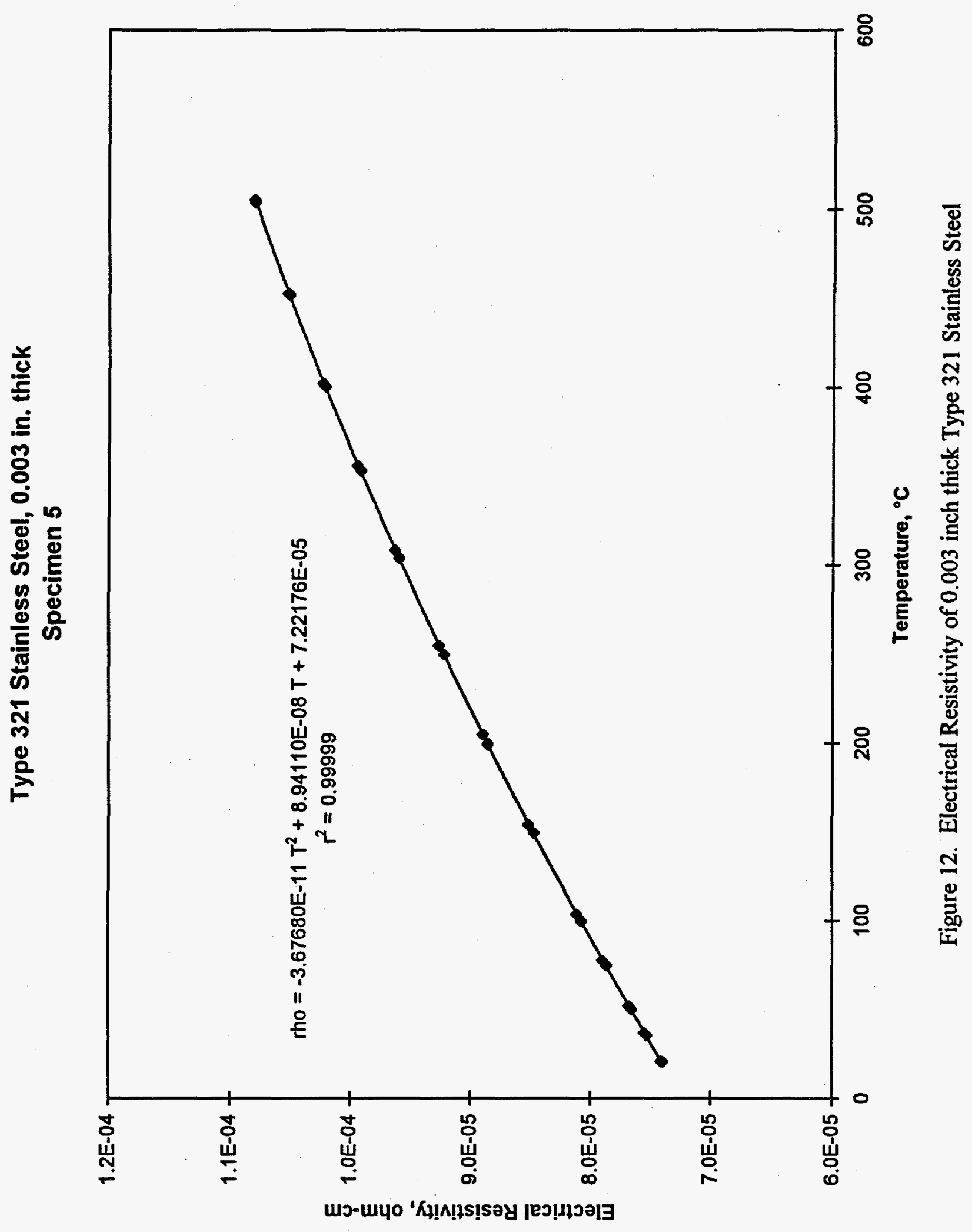


Type 321 Stainless Steel, 0.002 in. thick

Specimen 6

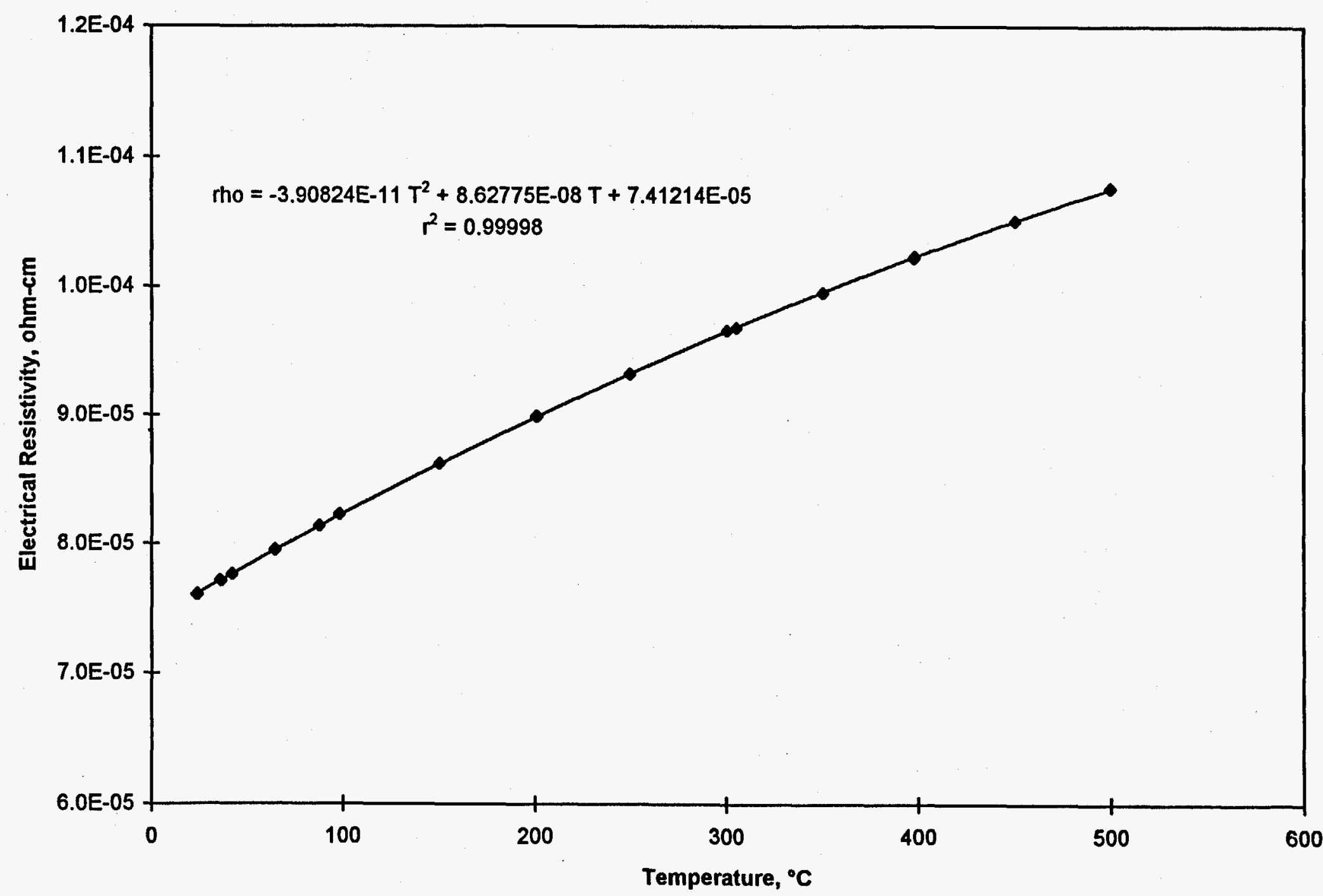

Figure 13. Electrical Resistivity of 0.002 inch thick Type 321 Stainless Steel 
Table 4. Deviation (percent) between Measured Electrical Resistivity and CINDAS Recommended Values

\begin{tabular}{|c|c|c|c|c|c|c|}
\hline $\begin{array}{c}\text { Tempera- } \\
\text { ture, }{ }^{\circ} \mathrm{C}\end{array}$ & $\begin{array}{c}\text { Specimen } \\
1\end{array}$ & $\begin{array}{c}\text { Specimen } \\
2\end{array}$ & $\begin{array}{c}\text { Specimen } \\
3\end{array}$ & $\begin{array}{c}\text { Specimen } \\
4\end{array}$ & $\begin{array}{c}\text { Specimen } \\
5\end{array}$ & $\begin{array}{c}\text { Specimen } \\
6\end{array}$ \\
\hline 25 & -0.8 & 1.9 & -0.5 & +4.7 & -0.8 & 1.6 \\
\hline 100 & -0.7 & 1.9 & -0.5 & +4.1 & 0.2 & 2.1 \\
\hline 200 & -0.6 & 1.9 & -0.5 & +3.5 & 1.2 & 2.6 \\
\hline 300 & -0.7 & 1.8 & -0.4 & +3.1 & 2.0 & 2.8 \\
\hline 400 & -0.7 & 1.6 & -0.3 & +2.8 & 2.5 & 2.8 \\
\hline 500 & -0.9 & 1.4 & -0.2 & +2.6 & 2.9 & 2.7 \\
\hline
\end{tabular}

Table 5. Variation of Electrical Resistivity along Specimen Length (Normalized to Resistivity of Center Section)

\begin{tabular}{|c|c|c|c|c|c|c|}
\hline Section & $\begin{array}{c}\text { Specimen } \\
1\end{array}$ & $\begin{array}{c}\text { Specimen } \\
2\end{array}$ & $\begin{array}{c}\text { Specimen } \\
3\end{array}$ & $\begin{array}{c}\text { Specimen } \\
4\end{array}$ & $\begin{array}{c}\text { Specimen } \\
5\end{array}$ & $\begin{array}{c}\text { Specimen } \\
6\end{array}$ \\
\hline 1 & 1.00325 & 1.00376 & 1.01110 & 1.02153 & 1.01592 & - \\
\hline 2 & 1.00197 & 0.99892 & 1.00288 & 1.01765 & 1.01245 & 1.00401 \\
\hline 3 & 0.99884 & 0.99711 & 1.00221 & 1.00680 & 1.00200 & 1.00105 \\
\hline 4 & 1.00000 & 1.00000 & 1.00000 & 1.00000 & 1.00000 & 1.00000 \\
\hline 5 & 1.00003 & 1.00681 & 1.00286 & 1.00543 & 1.00419 & 1.01132 \\
\hline 6 & 0.99946 & 1.01515 & 1.01114 & 1.00844 & 1.00748 & 1.01132 \\
\hline 7 & 1.00064 & 1.00465 & 1.01042 & 1.01399 & 1.01348 & 1.01132 \\
\hline
\end{tabular}


those for Specimen 4, which was made of Type 201, are 3 to 5 percent higher. The data for Specimens 5 and 6 , which were made of Type 321, are within \pm 3 percent of the CINDAS values. Considering the small thickness of the present specimens, this level of agreement is considered to be very good. For example, the measured values of resistivity are proportional to the specimen thickness, and an error of 3 percent in the thickness of Specimen 5 could be due to a thickness uncertainty of less than 0.0001 in.

Another result of the electrical resistivity measurements was that they could be used to quantify variations in the width of the specimens. Electrical resistivities were calculated for each section between adjacent thermocouples. Resistivity data at low temperatures showed systematic variations along the length of the specimen. Generally, the measured electrical resistivity was larger near the ends of the specimen than in the center. This is shown by the data in Table 5 , where the seven segments correspond to the spaces between the eight thermocouples. Since the temperature variations were small at low temperatures, these variations were not due to the temperature dependence of the resistivity. Rather, these systematic variations appear to be due to the specimen being wider at the center than at the ends. This was confirmed by direct measurements of the specimen width. The variation may be due to the clamping arrangement that was used in fabricating the specimens. If the ends were held fixed by pins through the two holes, then the middle might flex under the action of the cutting tool, allowing the middle to be wider. Even though these variations in width were small, it was found to be necessary to include this factor in the analysis for thermal conductivity.

\subsubsection{Total Hemispherical Emittance}

Results of the total hemispherical emittance measurements are given in Figures 14 through 19. Run 1 corresponds to data obtained upon heating the specimen up to $500^{\circ} \mathrm{C}$, and Run 2 corresponds to cooling back to room temperature. In all cases, the emittance for Run 2 was slightly lower than that for Run 1 . Since the emittance depends on the condition of the specimen surface, it is possible that heating the specimens to $500^{\circ} \mathrm{C}$ in vacuum drove off some surface contamination or changed the thickness of the protective oxide film, resulting in a lower emittance. 


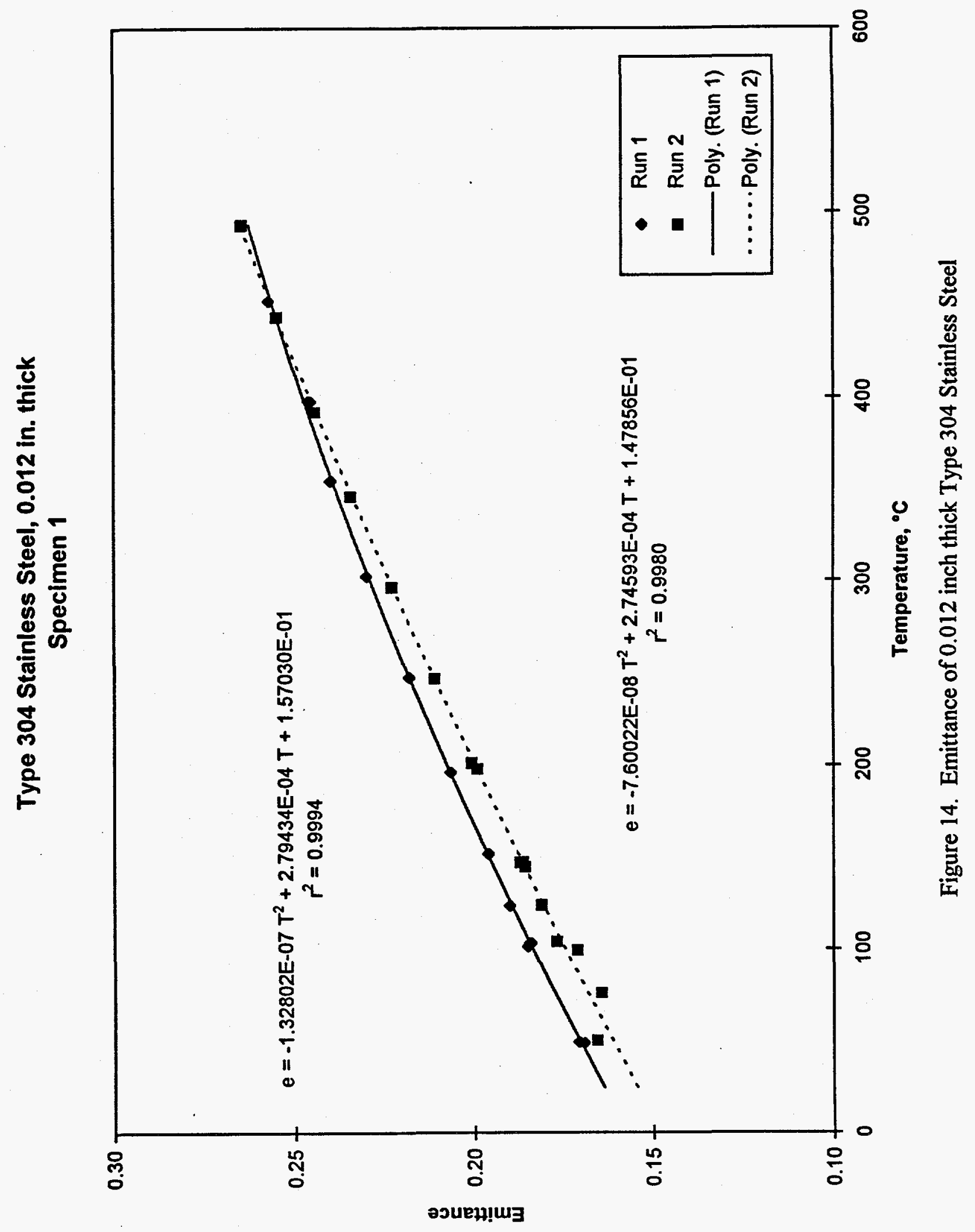


Type 304 Stainless Steel, 0.008 in. thick

Specimen 2

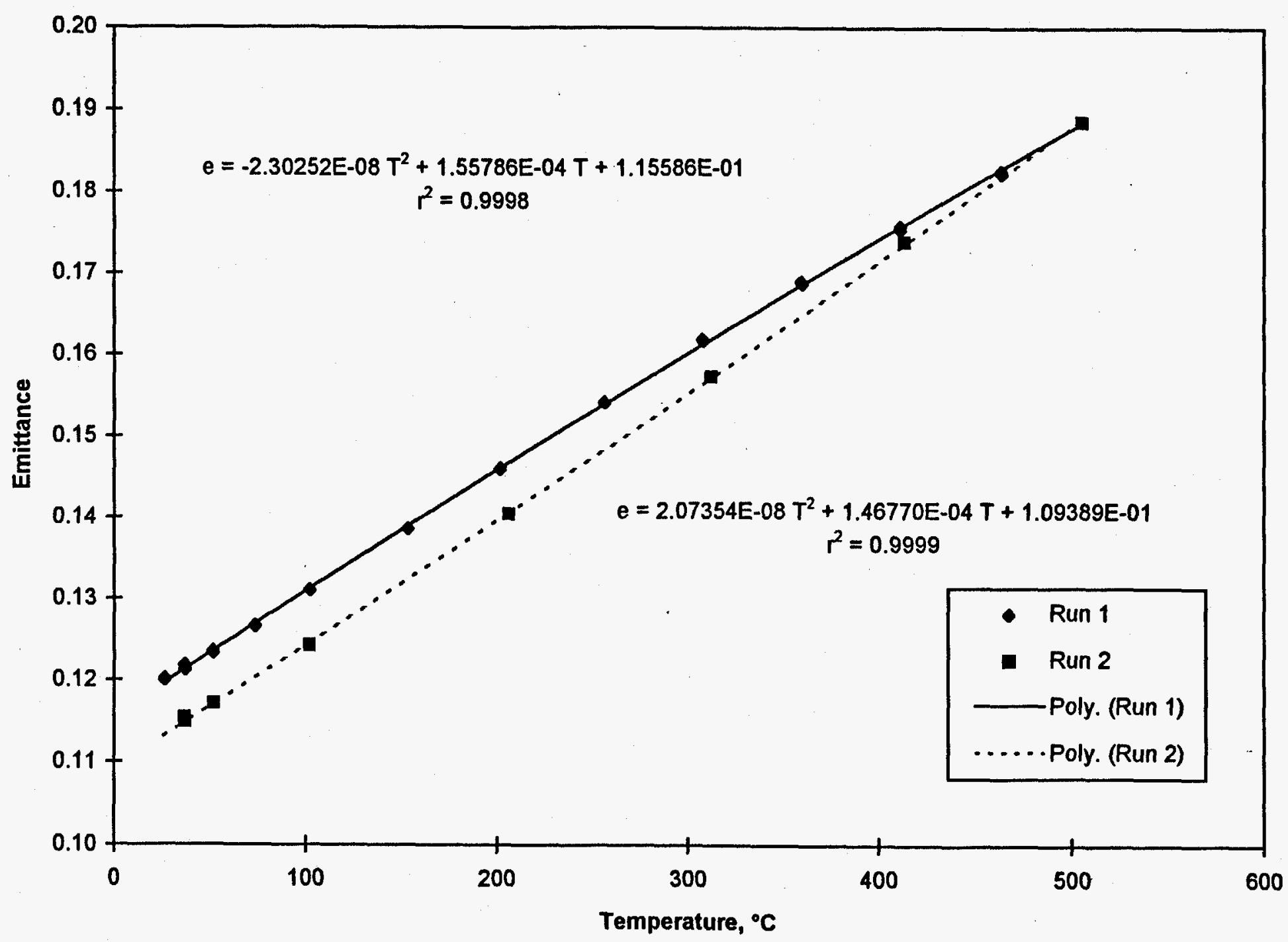

Figure 15. Emittance of 0.008 inch thick Type 304 Stainless Steel 


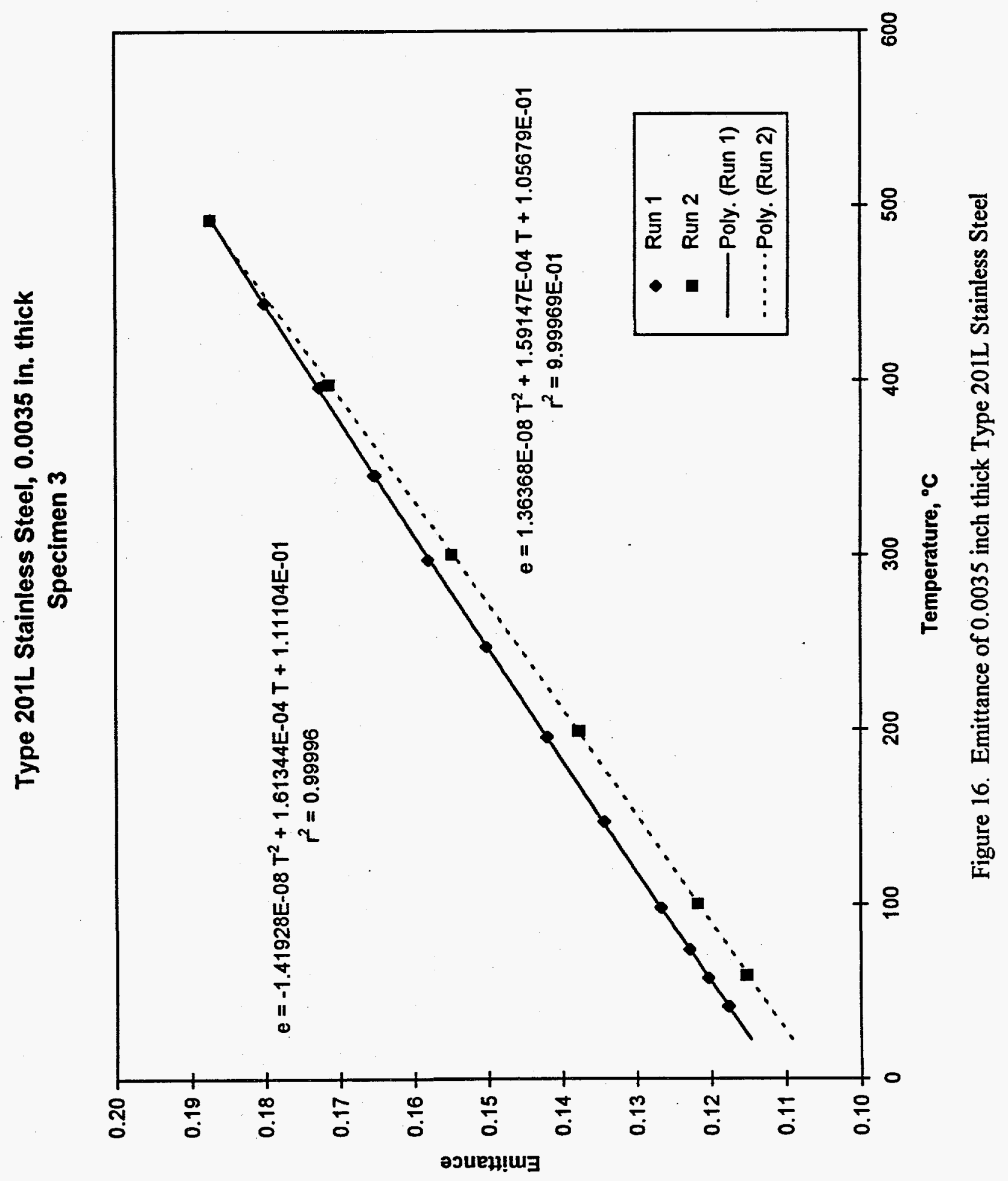


Type 201 Stainless Steel, 0.003 in. thick

Specimen 4

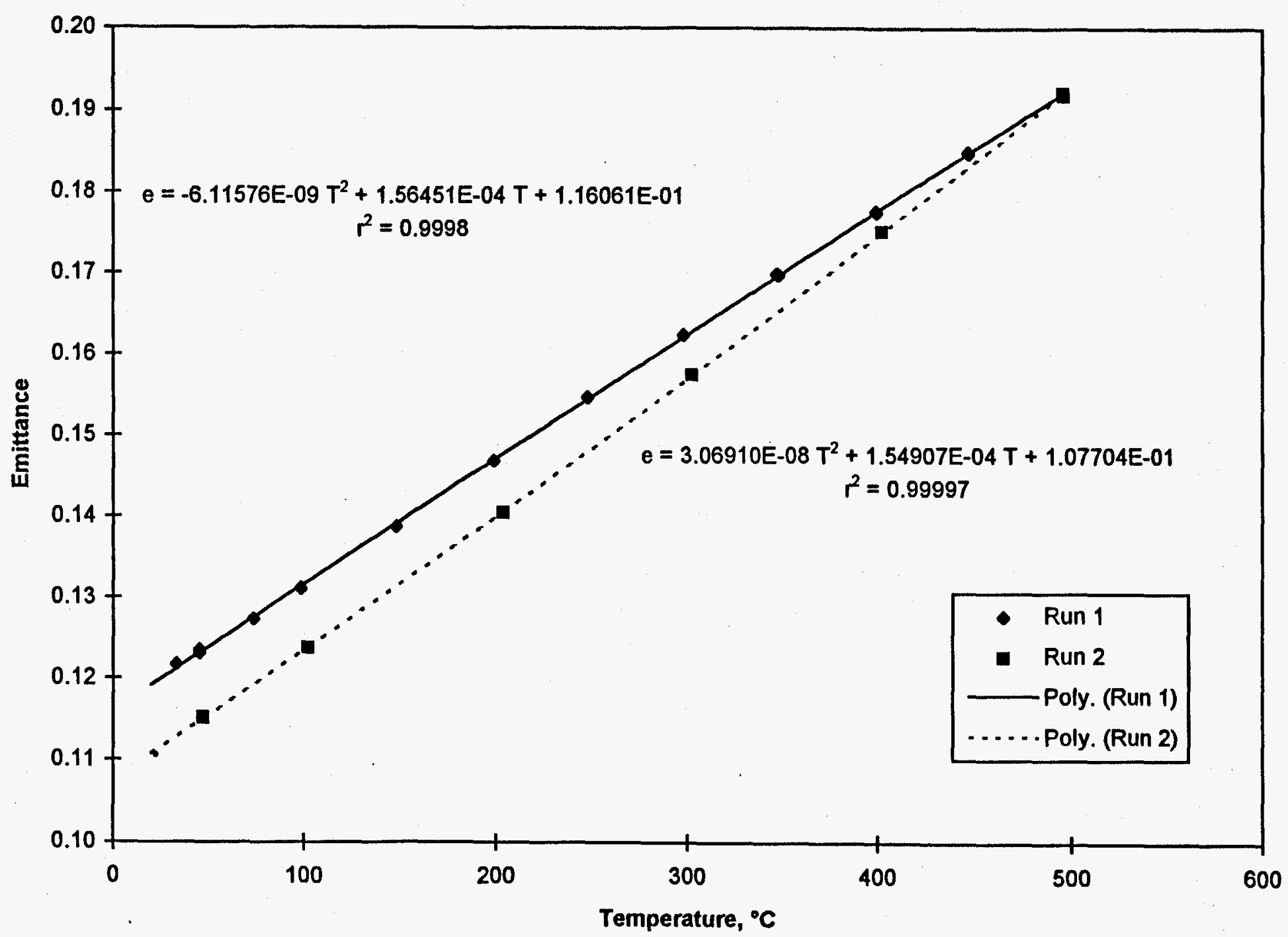

Figure 17. Emittance of 0.003 inch thick Type 201 Stainless Steel 
Type 321 Stainless Steel, 0.003 in. thick

Specimen 5

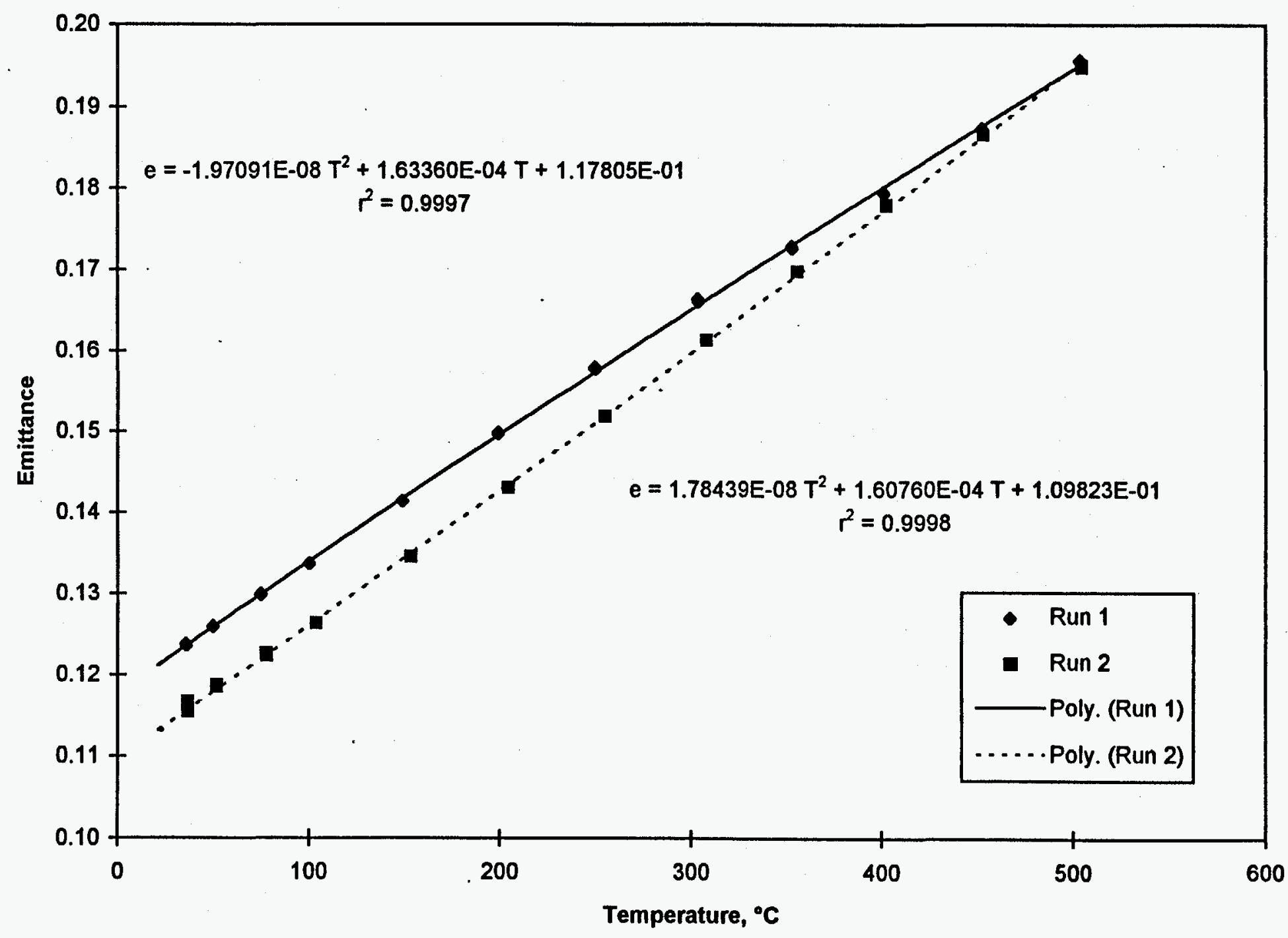

Figure 18. Emittance of 0.003 inch thick Type 321 Stainless Steel 
Type 321 Stainless Steel, 0.002 in. thick

Specimen 6

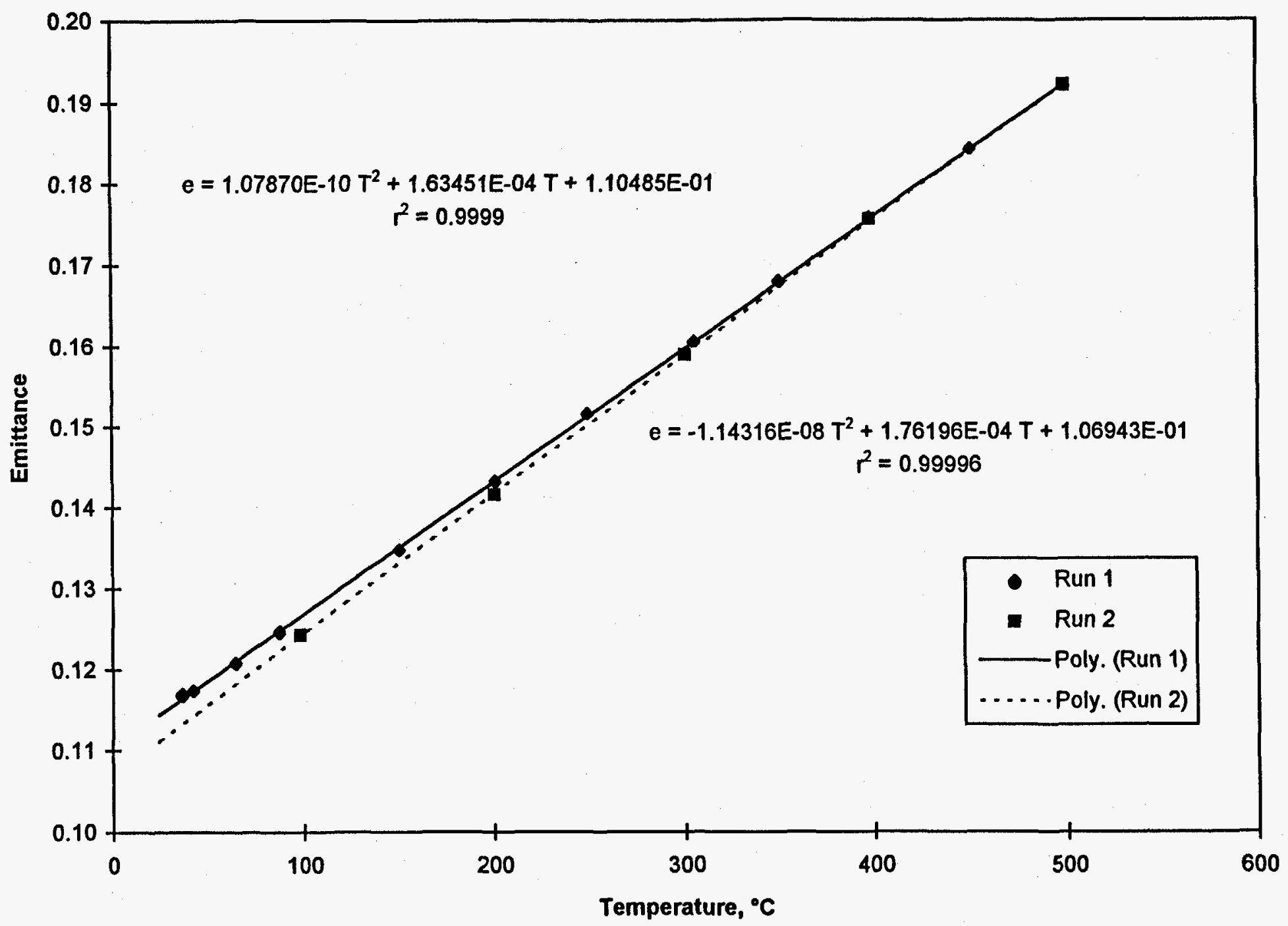

Figure 19. Emittance of 0.002 inch thick Type 321 Stainless Steel 
Data from Run 2 for the six specimens are compared in Figure 20 with predictions from electromagnetic field theory. The Schmidt-Eckert equation [11] relates the total normal emittance $\left(\epsilon_{n}\right)$ to electrical resistivity $(\rho)$ and absolute surface temperature $\left(T_{2}\right)$ through

$$
\epsilon_{\mathrm{n}}=0.576 \sqrt{\rho \mathrm{T}_{\mathrm{s}}}-0.124 \rho \mathrm{T}_{\mathrm{s}}
$$

where $\rho$ is in ohm-cm and $T$, is in degrees Kelvin. The CINDAS recommended electrical resistivity curve for Type $\mathbf{3 0 4}$ was used to calculate the theoretical curve in Figure 20. Figure 20 shows that the emittances of Specimens 2 through 6 are very similar and their variation with temperature parallels the theoretical curve. The emittance for Specimen 1 is considerably higher, but still has the same basic variation with temperature. The difference between the experimental and theoretical curves can be attributed to two factors. The first is that the experimental data are total hemispherical emittances (i.e., for radiation that is emitted in all directions from the surface), while the theoretical curve is for the total normal emittance (i.e., the radiation emitted only in a direction perpendicular to the surface). For perfectly flat, clean surfaces, electromagnetic theory predicts that the total hemispherical emittance will be about 20 percent larger than the normal emittance for the magnitude of emittances typical of stainless steel. This factor explains half or more of the difference between the theoretical curve and the data for Specimens 2 through 6 . The other factor not included in the theoretical curve is surface contamination, oxide films, and surface roughness, which usually make the emittance higher than the value obtained from electromagnetic theory. It appears that the surface condition of Specimen 1 was significantly different from that of the other five specimens, possibly because of a different mill finish.

\subsubsection{Thermal Conductivity Results}

Thermal conductivity results for Specimens 1 through 6 are given in Figures 21 through 26. The thermal conductivity values are given in units of $\mathrm{W} / \mathrm{cm} \cdot{ }^{\circ} \mathrm{C}$; to convert to Btu・in. $/ \mathrm{h} \cdot \mathrm{ft}^{2 \cdot{ }^{\circ} \mathrm{F}}$ units, multiply by 693.3 , and to convert to $\mathrm{Btu} / \mathrm{h} \cdot{ }^{\circ} \bullet{ }^{\circ} \mathrm{F}$, multiply by 57.78 . The data were fitted to equations linear in temperature by the method of least squares, and the resulting equations and coefficients of determination are given on the figures. As with the electrical resistivity, there was 


\section{Comparison of Measured Emittance with Schmidt-Eckert Theory}

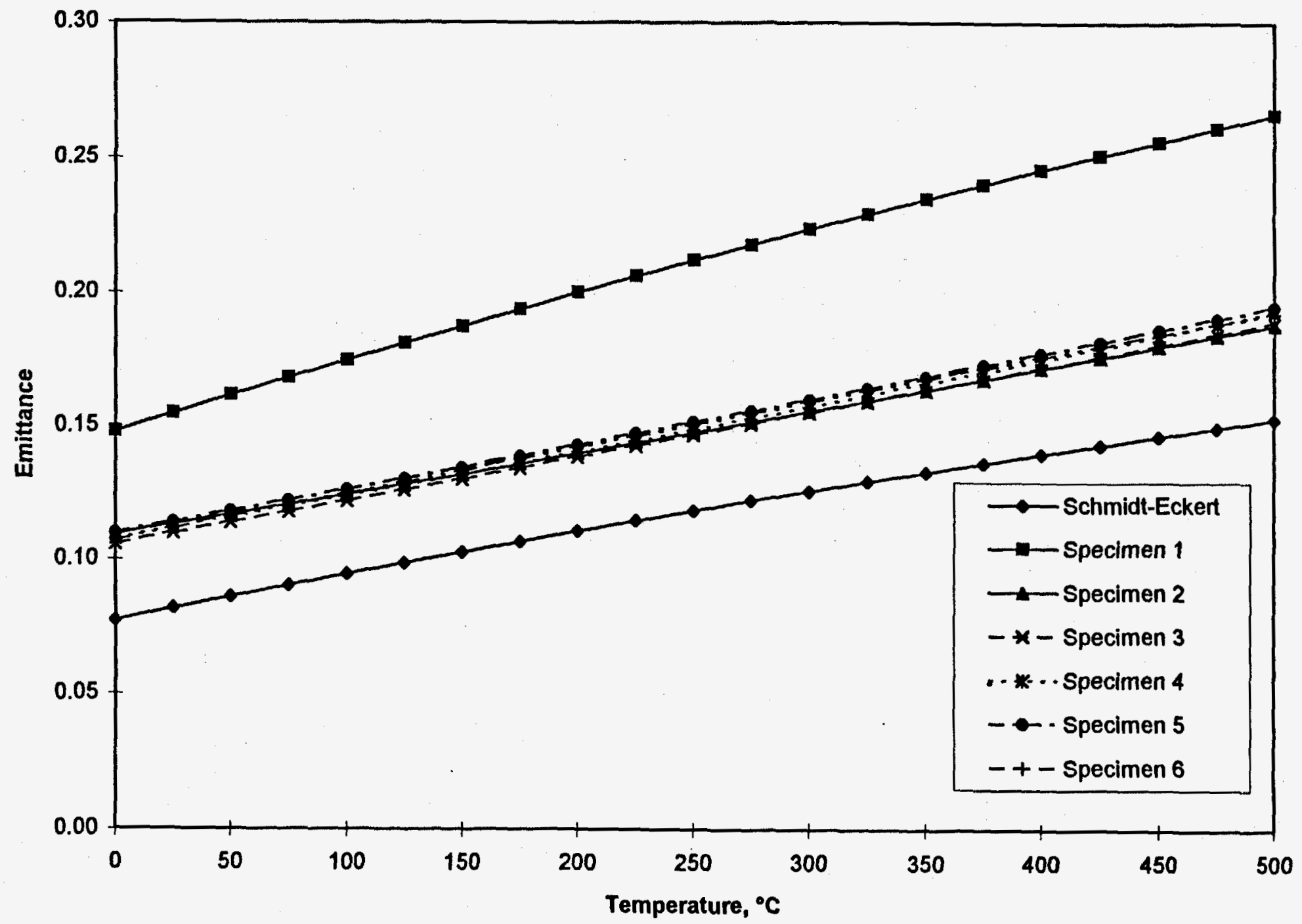

Figure 20. Comparison of Measured Total Hemispherical Emittance with Total Normal Emittance Calculated from Electromagnetic Theory 
Type 304 Stainless Steel, 0.012 in. thick

Specimen 1

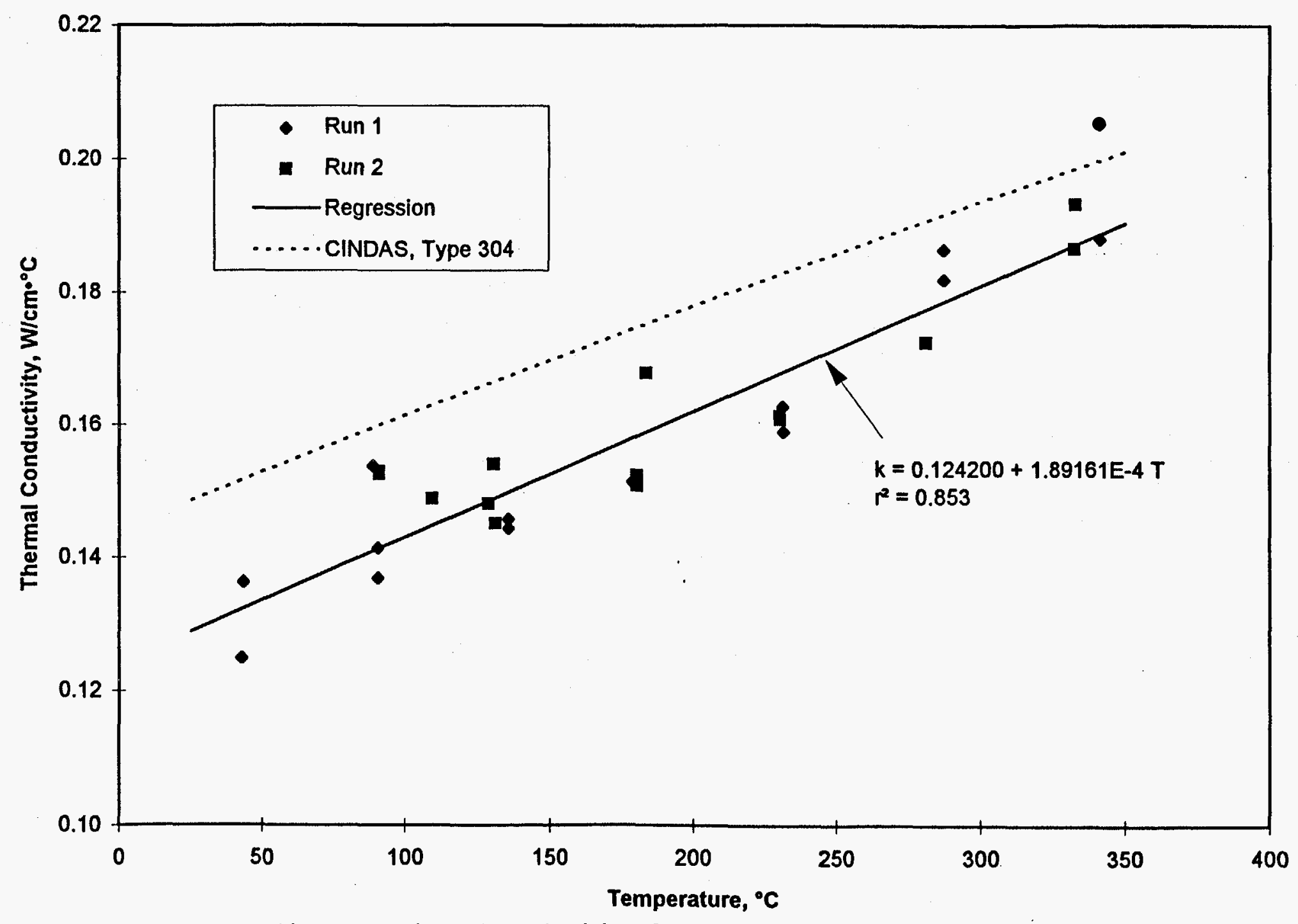

Figure 21. Thermal Conductivity of 0.012 inch thick Type 304 Stainless Steel 


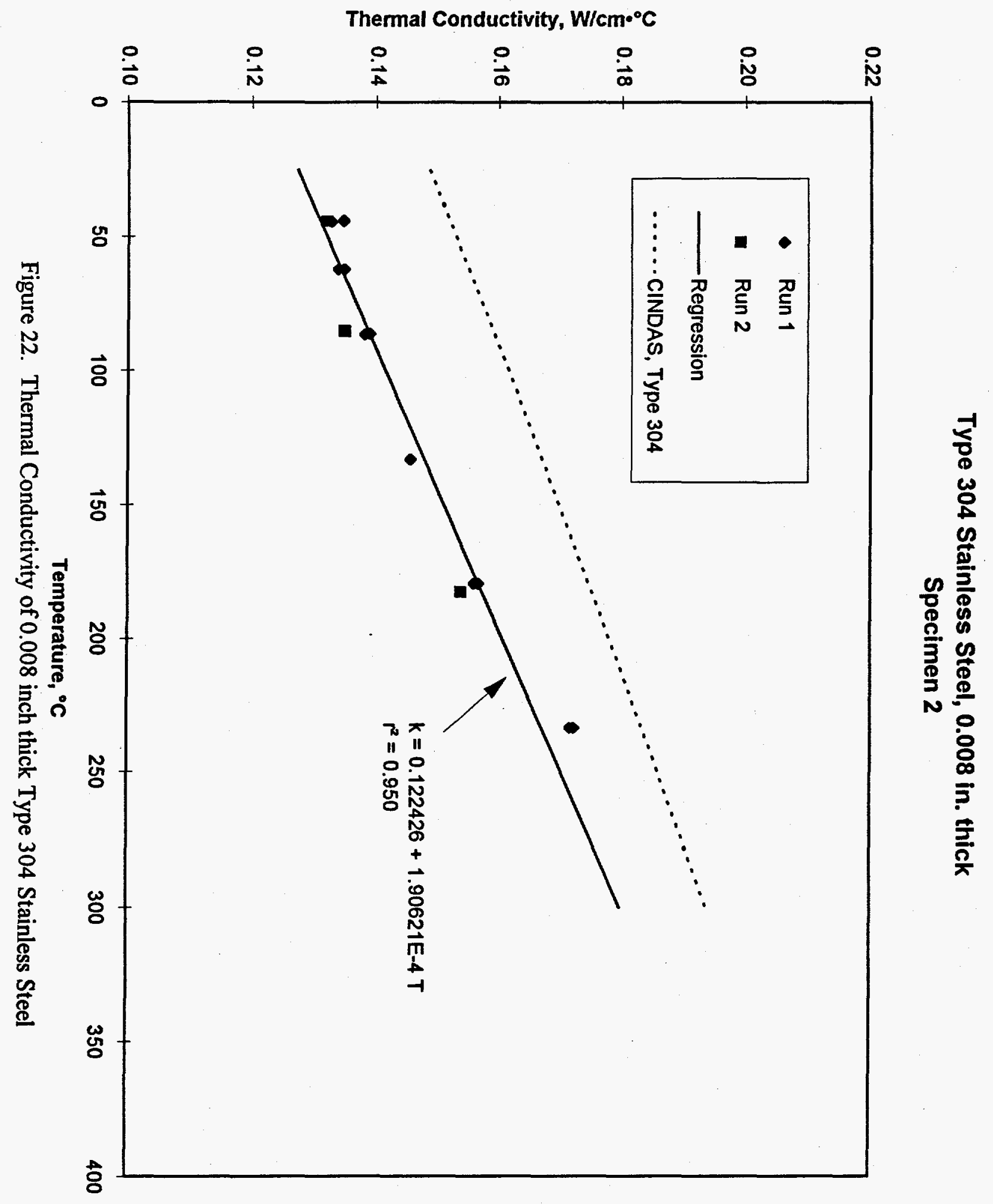


Thermal Conductivity, $\mathrm{W} / \mathrm{cm} \cdot{ }^{\circ} \mathrm{C}$

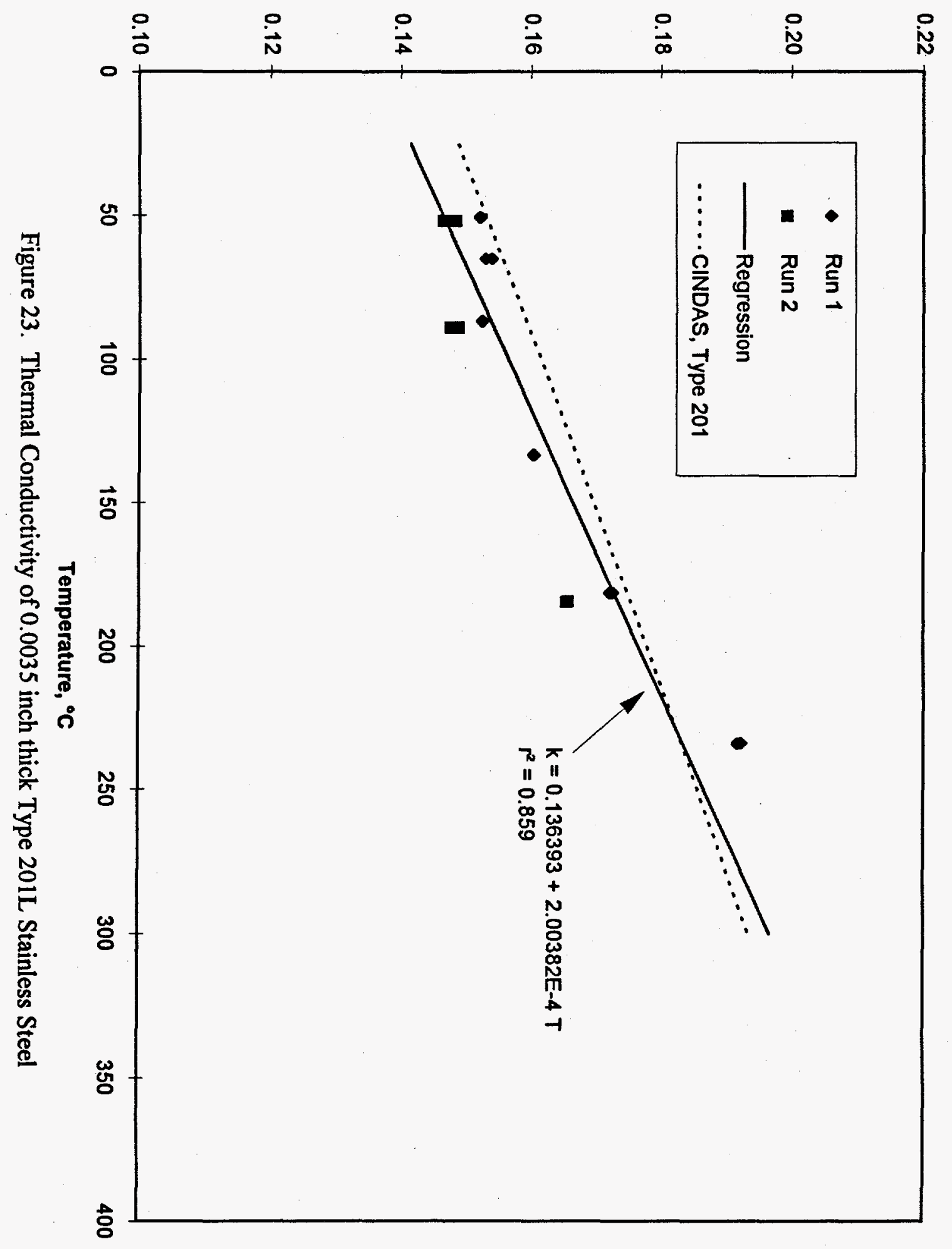

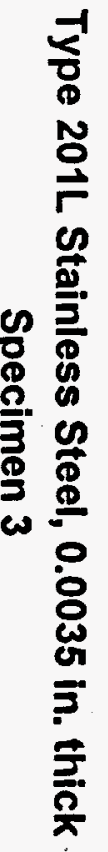


Type 201 Stainless Steel, 0.003 in. thick Specimen 4

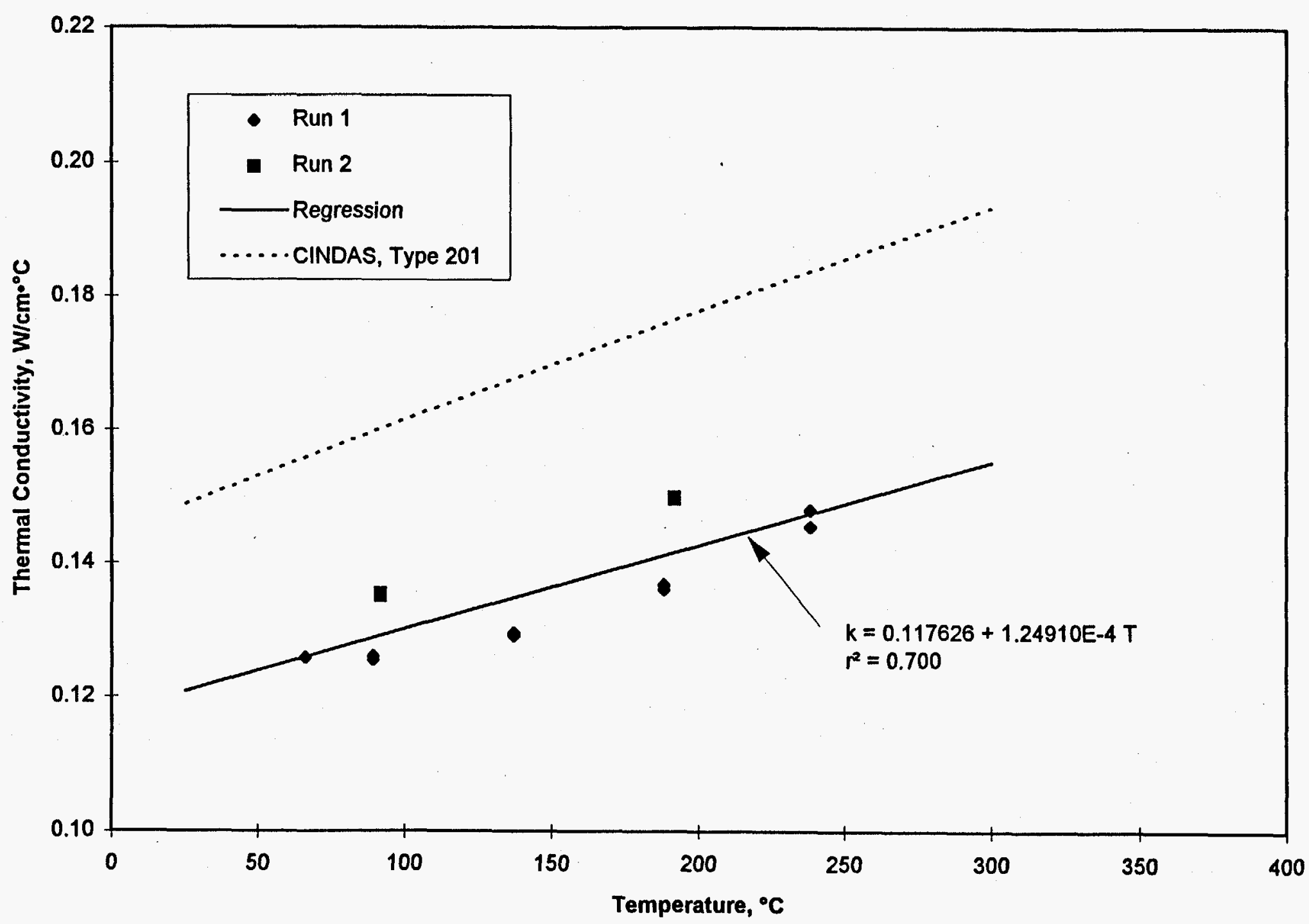

$\ddot{w}$

Figure 24. Thermal Conductivity of 0.003 inch thick Type 201 Stainless Steel 


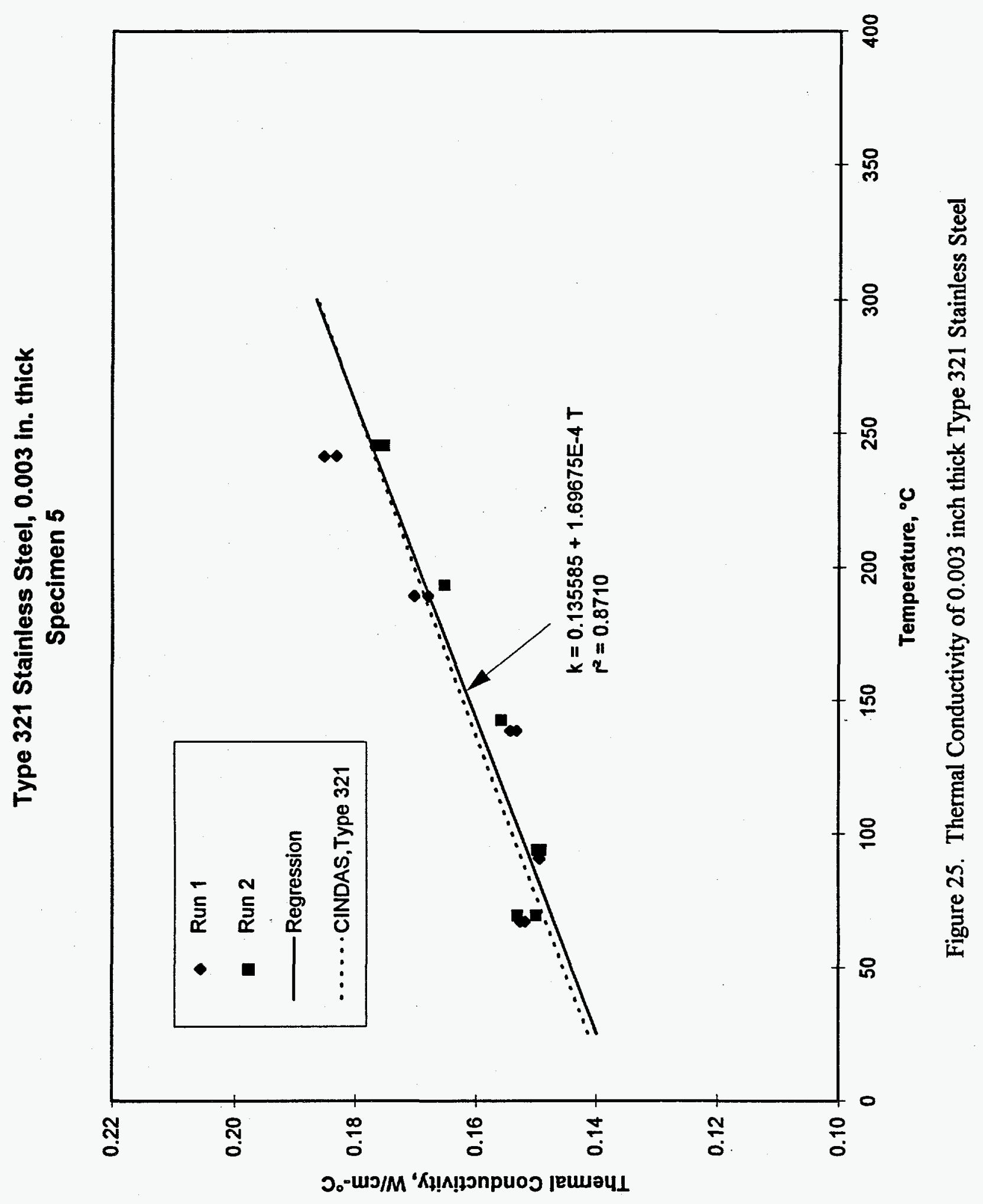




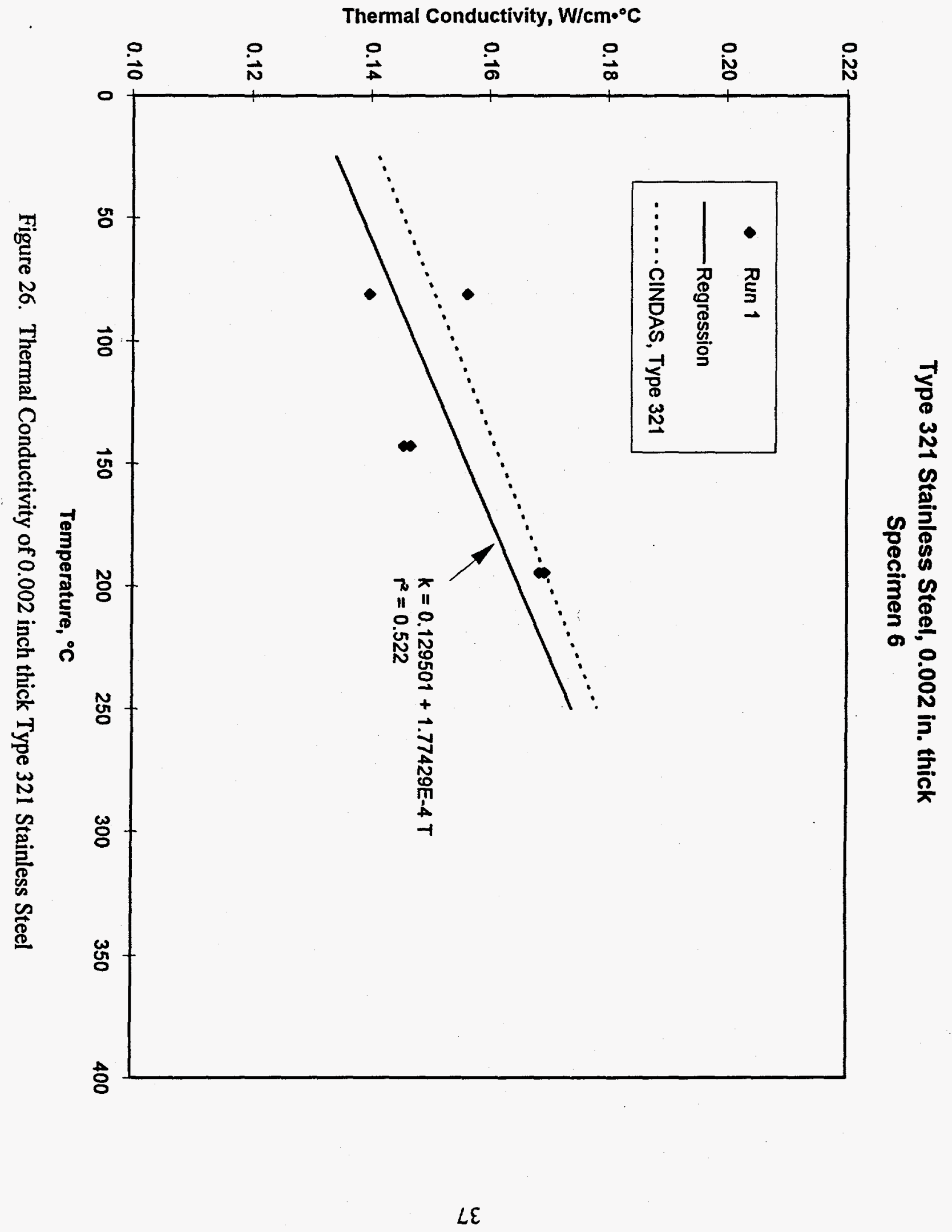


no discernible difference between the thermal conductivity values obtained upon heating to $500^{\circ} \mathrm{C}$ (Run 1) and those obtained upon cooling back to room temperature (Run 2).

The thermal conductivity data are less precise than either the electrical resistivity or emittance data. The resistivity and emittance data were obtained from measurements on the nearly isothermal central section of the specimen. Calculation of the thermal conductivity relies upon having accurate data for the resistivity and emittance, and on having accurate knowledge of the temperature profile. At the lower temperatures, the temperature profile was measured accurately, but the emittance data had less accuracy than at higher temperatures. Because of the lower accuracy of the emittance data, valid thermal conductivity data were obtained only above about $50^{\circ} \mathrm{C}$. At the higher temperatures, the emittance values were more accurate, but the temperature profile became less well known as the profile became flatter in the middle and steeper at the ends. Because of the lower accuracy in defining the temperature profile, valid conductivity data could only be obtained up to about 250 to $350^{\circ} \mathrm{C}$. Only a limited amount of thermal conductivity data were obtained for Specimen 6 . This was due to difficulties in welding thermocouples to this very thin specimen (the thermocouple wires were 0.003 in. diameter, making them 50 percent larger than the specimen thickness). As a consequence, several of the thermocouples became detached from the specimen during the measurements.

The present data are compared with the CINDAS recommended values in Figures 21-26, and percentage differences between the regression curves and the CINDAS values are given in Table 6. For Specimens 1 and 2 (Type 304), the present values are 13 to 14 percent lower than the CINDAS value near room temperature and are within 7 percent at $300^{\circ} \mathrm{C}$. For Specimen 3 (Type 201L), the present values are within 5 percent of the CINDAS values, while those for Specimen 4 (Type 201) are about 20 percent lower than the CINDAS values. For Specimen 5 (Type 321), the present values are within 1 percent of the CINDAS values from room temperature to $300^{\circ} \mathrm{C}$. For Specimen 6 (also Type 321 ), the present values are within 7 percent over the limited temperature range for which we could obtain data. Except for Specimen 4, this level of agreement is considered to be very reasonable, considering the difficulties in making these measurements on specimens with such small thicknesses and also given that CINDAS estimated that their recommended values have an uncertainty of about \pm 5 percent. In addition, the 
Table 6. Deviation (percent) between Regression Curve for Measured Thermal Conductivity and CINDAS Recommended Values

\begin{tabular}{|c|c|c|c|c|c|c|}
\hline $\begin{array}{c}\text { Tempera- } \\
\text { ture, }{ }^{\circ} \mathrm{C}\end{array}$ & $\begin{array}{c}\text { Specimen } \\
1\end{array}$ & $\begin{array}{c}\text { Specimen } \\
2\end{array}$ & $\begin{array}{c}\text { Specimen } \\
3\end{array}$ & $\begin{array}{c}\text { Specimen } \\
4\end{array}$ & $\begin{array}{c}\text { Specimen } \\
5\end{array}$ & $\begin{array}{c}\text { Specimen } \\
6\end{array}$ \\
\hline 25 & -13.2 & -14.4 & -4.9 & -18.8 & -1.0 & -6.3 \\
\hline 100 & -11.4 & -12.4 & -3.1 & -19.4 & -0.9 & -5.5 \\
\hline 200 & -9.0 & -9.8 & -0.8 & -19.8 & -0.4 & -4.7 \\
\hline 300 & -6.6 & -7.2 & +1.7 & -19.7 & 0.2 & -4.3 \\
\hline
\end{tabular}

Table 7. Room Temperature $\left(75^{\circ} \mathrm{F}\right)$ Thermal Conductivity from Direct Measurements

\begin{tabular}{|c|c|c|c|c|}
\hline \multirow{2}{*}{ Specimen } & \multirow{2}{*}{ Alloy } & \multicolumn{3}{|c|}{ Therinal Conductivity } \\
\cline { 3 - 5 } & & $\mathrm{W} / \mathrm{cm} \cdot{ }^{\circ} \mathrm{C}$ & Btu・in. $/ \mathrm{h} \cdot \mathrm{ft}^{2} \cdot{ }^{\circ} \mathrm{F}$ & $\mathrm{Btu} / \mathrm{h} \cdot \mathrm{ft} \cdot{ }^{\circ} \mathrm{F}$ \\
\hline 1 & 304 & 0.129 & 89.2 & 7.44 \\
\hline 2 & 304 & 0.127 & 88.0 & 7.34 \\
\hline 3 & $201 \mathrm{~L}$ & 0.141 & 97.9 & 8.16 \\
\hline 4 & 201 & 0.121 & 83.6 & 6.97 \\
\hline 5 & 321 & 0.140 & 96.8 & 8.07 \\
\hline 6 & 321 & 0.134 & 92.7 & 7.72 \\
\hline Average & & 0.132 & 91.4 & 7.62 \\
\hline
\end{tabular}


CINDAS values are for the solution annealed condition, whereas the present specimens probably have some degree of cold-work. Cold-worked material would be expected to have a somewhat lower thermal conductivity than material in the solution annealed condition.

Room temperature thermal conductivity values in several units of interest are summarized in Table 7, where values were calculated from the regression equations. The average conductivity is $0.132 \mathrm{~W} / \mathrm{cm} \cdot{ }^{\circ} \mathrm{C}$, and the conductivities of the six specimens are within about \pm 8 percent of this value. These results show that there is not a great deal of variation of the room temperature thermal conductivity with either alloy type or foil thickness.

\subsection{Thermal Measurements on Evacuated Panels}

\subsubsection{Measurement Method}

Thermal measurements were made on steel-clad evacuated panels using a heat flow meter apparatus that conforms to ASTM C 518.[12] The method consists of sandwiching a flat specimen between two isothermal plates that are held at constant, but different, temperatures (usually $55^{\circ} \mathrm{F}$ and $95^{\circ} \mathrm{F}$ ). The heat flux through the specimen is measured using calibrated heat flux transducers. The thermal resistance, $R$, is then calculated from

$$
R=\frac{\Delta T}{q}
$$

where $\Delta T$ is the temperature difference across the specimen and $q$ is the heat flux (i.e., the heat flow per unit area).

Measurements on evacuated panels were made by sandwiching them within sheets of semi-rigid fiberglass insulation, as shown in Figure 27. A recess was cut into the middle sheet to accept the evacuated panel. Thermocouples were taped near the center of the top and bottom surfaces of the evacuated panel. Heat fluxes were measured using an array of four-inch-square heat flux transducers (HFTs) placed on the bottom plate of the apparatus. The arrangement of the heat flux transducer array with respect to the hot plate and the evacuated panel is shown in Figure 28. 


\section{Cold plate, $55^{\circ} \mathrm{F}$}

Fiberglass insulation

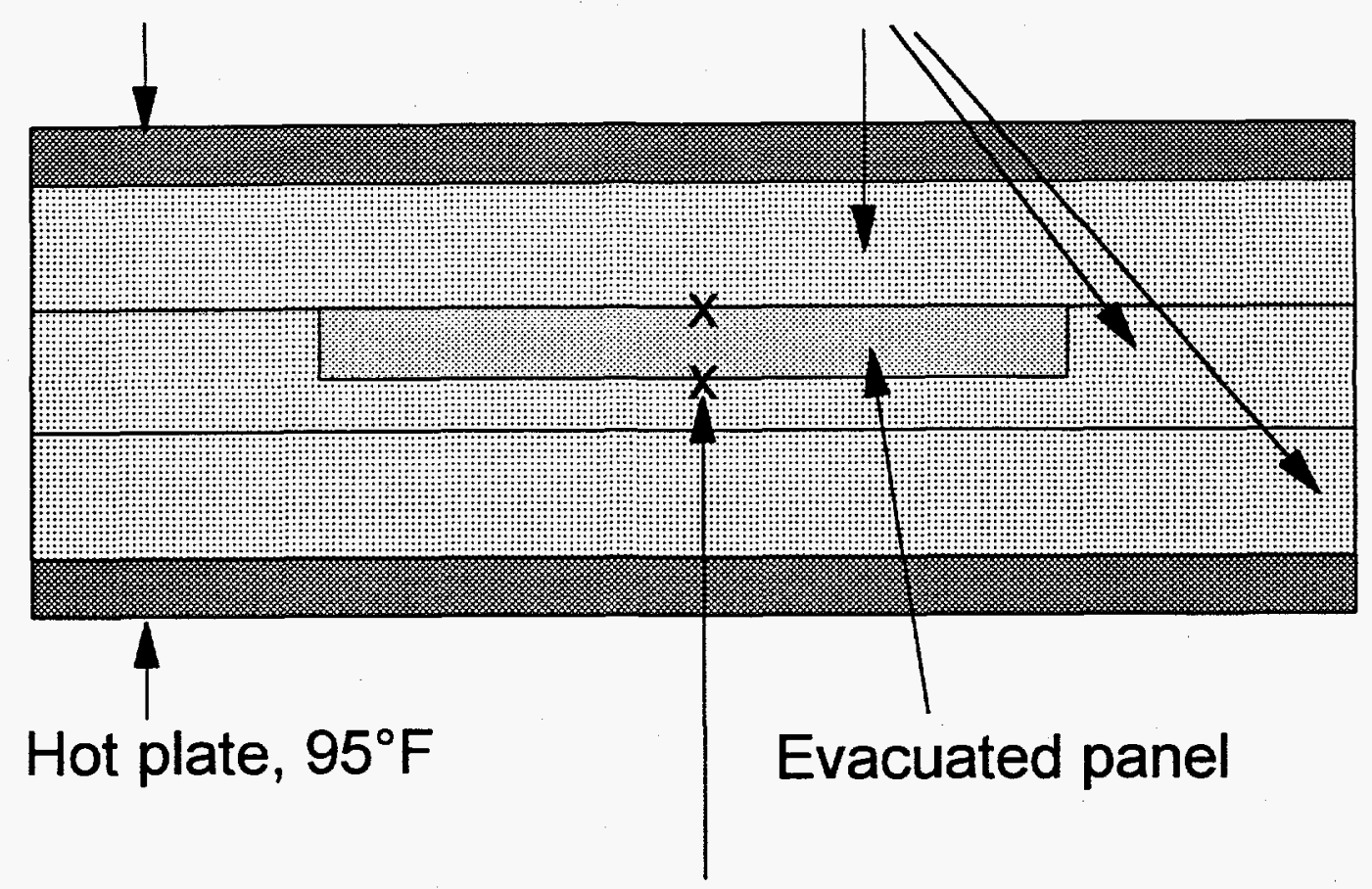

Thermocouples

Figure 27. Arrangement of Heat Flow Meter Apparatus for Tests on Evacuated Panels. The hot and cold plates are 24 inches square. The total insulation thickness is 2.5 inches. 
Hot and cold plates,

24 in. sq.

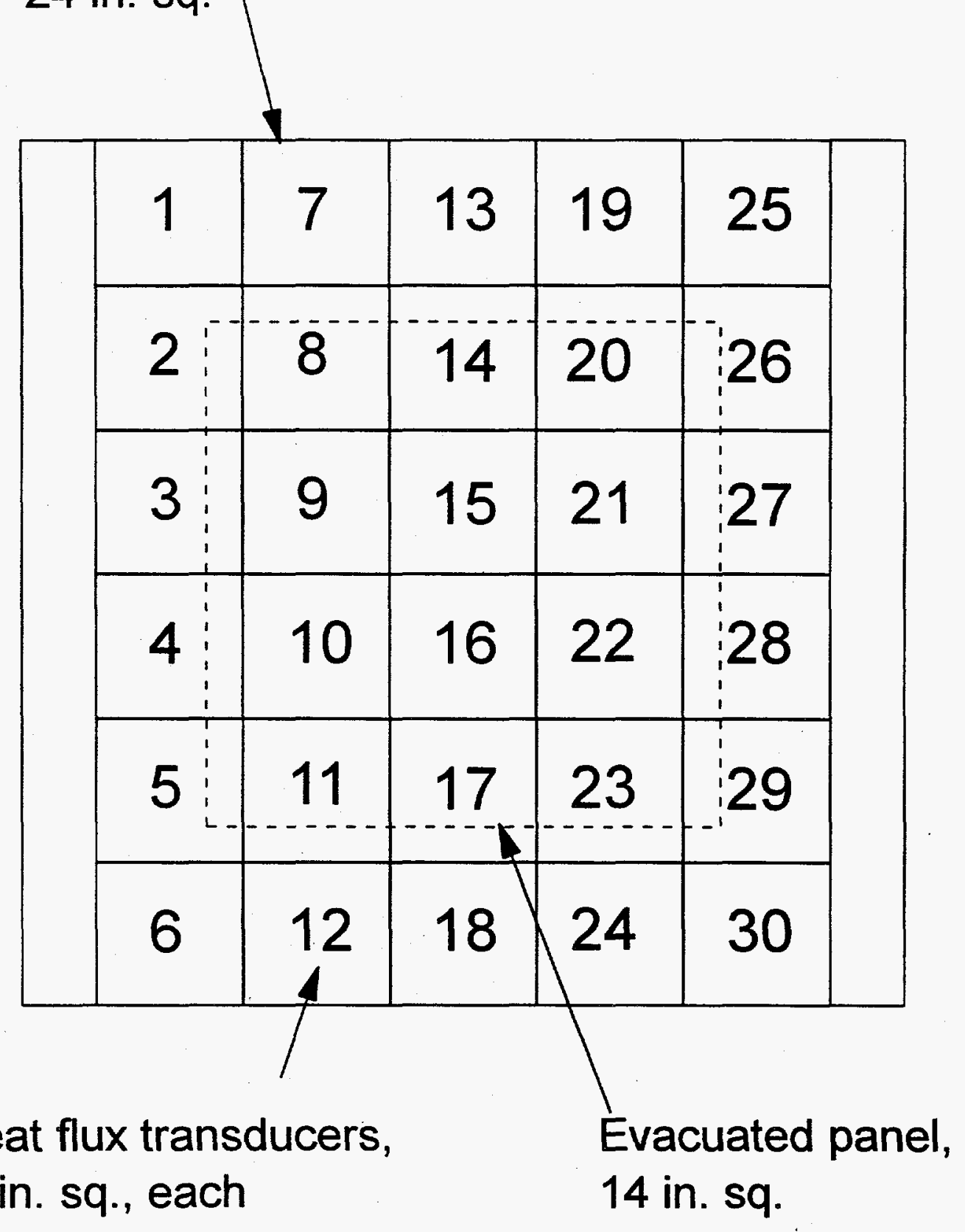

Figure 28. Arrnangement of Heat Flow Meter Apparatus for Measurements on Evacuated Panels 


\subsubsection{Test Panels}

Aladdin furnished seven evacuated panels for this phase of the program. Characteristics of the panels are given in Table 8. All panels were about 14 inches square, exclusive of the flange on the flat side. The average panel thickness, based on measurements at 12 locations over the surface of the panel, ranged from 0.37 to 0.56 inches. The pan-shaped sides of Panels 18 and 20 were greatly distorted, giving very nonuniform thicknesses, especially near the edges. The panshaped sides of all panels were made of stainless steel, using either Type 304, 201, or 201L at 0.003 to 0.008 inches thick. For all panels except 18 and 20 , the flat-side cladding was made of the same alloy and thickness as the pan-shaped side. For Panel 18, the flat side was made of 0.012 inch thick Type 304, and for Panel 20, the flat side was made of 0.017 inch thick coldrolled steel. Three types of fillers (unspecified) were used for the panels, as shown in Table 8.

\subsubsection{Heat Transmission Results}

The results of tests in the heat flow meter apparatus are given in Table 9. The quantities labeled "center-of-panel" were obtained by using the temperature difference measured across the evacuated panel and the heat flux measured over the central 4 inch by 8 inch area (i.e., HFTs 15 and 16). This corresponds to the traditional method for reporting center-of-panel resistances for evacuated panel insulations. The center-of-panel resistivities ranged from a low of 15 $\mathrm{h} \cdot \mathrm{ft}^{2 .}{ }^{\circ} \mathrm{F} / \mathrm{Btu} \cdot \mathrm{in}$. (R/in.) for Panel 20 to a high of $58 \mathrm{R} / \mathrm{in}$. for Panel 138. Panels with Filler Type C all had resistivities between 44 and $58 \mathrm{R} / \mathrm{in}$. With exception of Panel 20, resistivities for the other four panels were clustered around 23 to $25 \mathrm{R} / \mathrm{in}$.

Aladdin made heat transmission measurements using a 1-1/2 in. diameter gauge that was developed in-house. Center-of-panel values measured with the gauge were within \pm 17 percent of the heat flow meter apparatus results. Since the Aladdin gauge was designed to provide rapid determinations of relative panel performance rather than absolute values, the level of agreement with the heat flow meter results is considered to be reasonable.

Because of heat conduction around the edges of the panel through the stainless steel cladding, the overall panel resistivity will not be the same as the center-of-panel value. Also, because of the relatively small size of the panels, the measured center-of-panel value will be 
Table 8. Characteristics of Evacuated Panels

\begin{tabular}{|c|c|c|c|c|c|c|}
\hline \multirow{2}{*}{ Panel } & \multirow{2}{*}{$\begin{array}{c}\text { Panel } \\
\text { Thickness, } \\
\text { in. }\end{array}$} & \multicolumn{2}{|c|}{ Pan-Shaped Cladding } & \multicolumn{2}{|c|}{ Flat Cladding } & \multirow{2}{*}{ Filler } \\
\cline { 3 - 6 } & Thick., in. & Alloy & Thick., in. & Alloy & \\
\hline 18 & 0.406 & 0.004 & 304 & 0.012 & 304 & Type A \\
\hline 20 & 0.423 & 0.004 & 304 & 0.017 & Cold-rolled & Type B \\
\hline 24 & 0.373 & 0.008 & 304 & 0.008 & 304 & Type A \\
\hline 26 & 0.400 & 0.008 & 304 & 0.008 & 304 & Type B \\
\hline 138 & 0.535 & 0.004 & 304 & 0.004 & 304 & Type C \\
\hline 155 & 0.562 & 0.003 & 201 & 0.003 & 201 & Type C \\
\hline 222 & 0.512 & 0.0035 & $201 \mathrm{~L}$ & 0.0035 & $201 \mathrm{~L}$ & Type C \\
\hline
\end{tabular}

Note: All panels were approximately 14 inches square, exclusive of welding flange on flat side.

Table 9. Center-of-Panel and Filler Thermal Resistivities for Evacuated Panels

\begin{tabular}{|c|c|c|c|c|}
\hline \multirow{2}{*}{ Panel } & \multirow{2}{*}{$\begin{array}{c}\text { Measured } \\
\text { Center-of-Panel, } \\
\text { R/inch }\end{array}$} & \multicolumn{2}{|c|}{ Calculated Filler R/inch } & $\begin{array}{c}\text { Percent } \\
\text { Difference, } \\
\text { (Filler/Center-1) } \\
\times 100\end{array}$ \\
\cline { 3 - 5 } & 24.1 & $29.3 \pm 1.5$ & $36.8 \pm 3.2$ & $15-66$ \\
\hline 18 & 15.3 & $20.2 \pm 0.8$ & $27.8 \pm 2.0$ & $27-95$ \\
\hline 20 & 25.3 & $30.6 \pm 1.2$ & $36.8 \pm 3.0$ & $16-57$ \\
\hline 24 & 23.1 & $28.0 \pm 1.1$ & $32.6 \pm 2.4$ & $16-52$ \\
\hline 26 & 57.6 & $73.0 \pm 4.1$ & $83.1 \pm 11.3$ & $20-63$ \\
\hline 138 & 43.6 & $49.2 \pm 1.2$ & $52.3 \pm 3.8$ & $10-29$ \\
\hline 155 & 53.9 & $66.6 \pm 2.8$ & $70.0 \pm 7.1$ & $18-43$ \\
\hline 222 & & &
\end{tabular}

Note: Range of filler resistivities results from calculations with stainless steel thermal conductivity ranging from 6.4 to $8.6 \mathrm{Btu} / \mathrm{h} \cdot \mathrm{ft} \cdot{ }^{\circ} \mathrm{F}\left(0.11\right.$ to $\left.0.15 \mathrm{~W} / \mathrm{cm}{ }^{\circ} \mathrm{C}\right)$ 
somewhat less than the value that would be obtained for a very large panel where the edge conduction effects would not influence the heat flow in the center. The effects of edge heat conduction were analyzed using a special purpose finite difference heat conduction computer program. The computer program uses knowledge of the specimen assembly geometry, boundary temperatures, and the thermal conductivities of the cladding, filler, and surrounding material to calculate the heat flux distribution at the locations of the heat flux transducers. The thermal conductivity of the filler material will generally not be known, and the thermal conductivity of the cladding may or may not be known. Starting with initial estimates for the unknown thermal conductivities, the computer program systematically varies these conductivities and searches for the values that give the best match (in the least squares sense) between the calculated and measured heat flux distributions.

As the first step in this analysis, the program was used to estimate the thermal resistivity of the filler material. Since the resistivity of the filler material will be the same as the center-of-panel resistivity for a very large panel, the difference between the estimated filler material and the measured center-of-panel values is an indication of the loss in thermal performance because of heat conduction through the cladding material. For these calculations, the thermal conductivity of stainless steel was taken to be $7.5 \pm 1.1 \mathrm{Btu} / \mathrm{h} \cdot \mathrm{ft} \cdot{ }^{\circ} \mathrm{F}\left(0.13 \pm 0.02 \mathrm{~W} / \mathrm{cm} \cdot{ }^{\circ} \mathrm{C}\right)$. The value of 7.5 $\mathrm{Btu} / \mathrm{h} \cdot \mathrm{ft} \cdot{ }^{\circ} \mathrm{F}$ corresponds to the average thermal conductivity measured in Section 3.1, while \pm 1.1 $\mathrm{Btu} / \mathrm{h} \cdot \mathrm{ft} \cdot{ }^{\circ} \mathrm{F}$ represents the range of uncertainty in the measured values. The thermal conductivity of cold-rolled steel was taken to be $26.2 \mathrm{Btu} / \mathrm{h} \cdot \mathrm{ft} \cdot{ }^{\circ} \mathrm{F}$.[13] Results of these calculations are given in Table 9. Two values are given for the calculated filler $\mathrm{R} / \mathrm{in}$. For one calculation, the computer program tried to match the heat fluxes measured with only the two center heat flux transducers (HFTs 15 and 16). For the other calculation, the program tried to match all twenty heat flux transducers that were under the evacuated panel (HFTs 2-5, 8-11,14-17, 20-23, and 26-29). The last column gives the percentage difference between the calculated filler resistivity and the measured center-of-panel value. These calculations indicate that a very large panel would have a resistivity 10 to 95 percent larger than the measured center-of-panel values. This indicates that there is a significant effect of edge conduction on the heat flow over the center 4 inch by 8 inch area that is used for determining the measured center-of-panel values. The large range of 
percentage differences is caused by a combination of the uncertainty in the cladding thermal conductivity and the different values obtained by using different areas for the calculations. In general, the effect of different calculation areas is largest for those panels that have the most nonuniform thicknesses, i.e., Panels 18 and 20.

Of more practical interest is the calculated overall panel thermal resistivity, which is given in Table 10. The format for this table is the same as for Table 9. The effects of uncertainty in cladding thermal conductivity and of different calculational areas are much less for the calculation of overall panel resistivity than for the estimation of the filler resistivity. These results show that heat conduction through the cladding is estimated to cause the overall panel resistivity to be as much as 58 percent less than the measured center-of-panel values.

The computer program was also used to try to estimate the cladding thermal conductivity as well as the filler resistivity. Results of calculations using the heat fluxes measured with the center six transducers (HFTs 9, 10, 15, 16, 21, and 22) are given in Table 11. The results for Panels 138, 155, and 222 are very reasonable. The cladding thermal conductivities for these panels were within less than 30 percent of the directly measured values; the filler resistivities were within 8 percent of those estimated in Table 9; and the overall panel resistivities were within 8 percent of those estimated in Table 10. Results for the other panels were less reasonable. For Panels 18, 24, and 26, the cladding thermal conductivity is less than one-half of the directly measured values, but the overall panel resistivities were within three to 14 percent of those estimated in Table 10. For Panel 20, the program would not run. Attempts were made to perform these same calculations using heat fluxes measured with more of the transducers. However, the calculated cladding thermal conductivities were even less reasonable, even for Panels 138, 155, and 222.

As might be expected, the computer model only works well when the geometry of the panel conforms to the regular rectangular geometry that is built into the model. Panels 18 and 20 had very nonuniform thicknesses. They also had very thick flat sides, and, in the case of Panel 20, the flat side was made of a much higher thermal conductivity steel. For Panels 24 and 26, the stainless steel was still fairly thick. Thicker claddings and high thermal conductivity materials lead to a more isothermal flat surface, and hence more uniform heat fluxes. The basis of the computer 
Table 10. Center-of-Panel and Overall Panel Thermal Resistivities for Evacuated Panels

\begin{tabular}{|c|c|c|c|c|}
\hline \multirow{2}{*}{ Panel } & \multirow{2}{*}{$\begin{array}{c}\text { Measured } \\
\text { Center-of-Panel, } \\
\text { R/inch }\end{array}$} & \multicolumn{2}{|c|}{ Calculated Panel R/inch } & $\begin{array}{c}\text { Percent } \\
\text { Difference, } \\
(1-\text { Panel/Center }) \\
\times 100\end{array}$ \\
\cline { 3 - 5 } & 24.1 & $15.4 \pm 0.2$ & $17.5 \pm 0.1$ & $27-37$ \\
\hline 18 & 15.3 & $11.0 \pm 0.2$ & $13.2 \pm 0.1$ & $13-29$ \\
\hline 20 & 25.3 & $14.6 \pm 0.4$ & $16.1 \pm 0.2$ & $36-44$ \\
\hline 24 & 23.1 & $13.5 \pm 0.4$ & $14.7 \pm 0.2$ & $36-43$ \\
\hline 26 & 57.6 & $25.2 \pm 1.1$ & $26.2 \pm 0.5$ & $54-58$ \\
\hline 138 & 43.6 & $23.1 \pm 0.9$ & $23.7 \pm 0.3$ & $45-49$ \\
\hline 155 & 53.9 & $26.1 \pm 1.0$ & $26.5 \pm 0.5$ & $50-53$ \\
\hline 222 & & & & \\
\hline
\end{tabular}

Note: Range of panel resistivities results from calculations with stainless steel thermal conductivity ranging from 6.4 to $8.6 \mathrm{Btu} / \mathrm{h} \cdot \mathrm{ft} \cdot{ }^{\circ} \mathrm{F}\left(0.11\right.$ to $\left.0.15 \mathrm{~W} / \mathrm{cm}^{\circ}{ }^{\circ} \mathrm{C}\right)$

Table 11. Results of Computer Program Simultaneous Estimation of Cladding Thermal Conductivity, Filler Resistivity and Overall Panel Resistivity

\begin{tabular}{|c|c|c|c|}
\hline Panel & $\begin{array}{c}\text { Cladding Thermal } \\
\text { Conductivity, } \\
\text { Btu/h॰f॰ }{ }^{\circ} \mathrm{F}\end{array}$ & $\begin{array}{c}\text { Filler Resistivity, } \\
\text { R/inch }\end{array}$ & $\begin{array}{c}\text { Overall Panel } \\
\text { Resistivity, } \\
\text { R/inch }\end{array}$ \\
\hline 18 & 2.96 & 24.2 & 16.9 \\
\hline 20 & - & - & - \\
\hline 24 & 2.57 & 26.5 & 17.5 \\
\hline 26 & 3.55 & 24.9 & 15.4 \\
\hline 138 & 8.35 & 76.2 & 24.2 \\
\hline 155 & 8.81 & 50.8 & 22.1 \\
\hline 222 & 9.85 & 73.4 & 24.1 \\
\hline
\end{tabular}

Note: Based on heat fluxes measured with central six heat flux transducers. 
program is that it relies on heat flux variations to estimate the cladding conductivity. As these variations are reduced, the ability of the program to reliably estimate the cladding conductivity is reduced. From these results, the computer program appears to be useful for estimating the cladding conductivity when the panel has a uniform thickness, the cladding is fairly thin (i.e., around 0.004 in.), and the cladding on both sides of the panel is the same metal. However, directly measured values of the cladding thermal conductivity are to be preferred.

\subsection{Refrigerator Simulations}

\subsubsection{Energy Savings Due to Evacuated Panels}

The EPA Refrigerator Analysis (ERA) Program [14] was used to estimate the energy savings that could be expected due to the application of evacuated panel insulations in the walls and doors of refrigerators. The ERA program was designed to allow comparisons of the performance potential of alternate cabinet and cycle designs. It combines an analysis of the refrigerator load requirements of the cabinet with a simulation of the capacity and efficiency of the refrigeration cycle. One specific feature that was built into ERA was the capability of analyzing the effects of advanced insulation materials.

For a baseline, we used the $18 \mathrm{ft}^{3}$, top mount refrigerator labeled 1993 Model A (typical), as described in Reference 15. An $18 \mathrm{ft}^{3}$ top mount refrigerator was chosen for a baseline because it is representative of those currently available commercially. Approximately 40 percent of the market is for this size of refrigerator/freezer, and it is the most popular size purchased.[16] The specifications for this refrigerator were developed by EPA by modifying an actual 1991 model to meet the 1993 energy standards. Key characteristics of the 1993 model are given in Table 12.

The energy usage for this model as calculated by the ERA program is $650 \mathrm{kWh}$ per year for the conditions of the DOE $90^{\circ} \mathrm{F}$ closed door test. This is below the 1993 DOE energy standard of $684 \mathrm{kWh}$ per year. For the simulations reported here, we changed the ambient temperature to a more reasonable value to simulate the interior of a house, and added door opening schedules. The changes that were made are detailed in Table 13. Temperatures with the fresh food and freezer compartments were left unchanged at $38^{\circ} \mathrm{F}$ and $5^{\circ} \mathrm{F}$, respectively. With these revised conditions, the annual energy usage was $671 \mathrm{kWh}$. 
Table 12. Characteristics of Refrigerator Used for Simulations of Energy Savings with Evacuated Panels

Storage Volume:

Insulation $\mathrm{R} / \mathrm{inch}$ :

Insulation Volume:

Cabinet Height

Cabinet Width:

Cabinet Depth:

Outer Surface Area:

Compressor Design:

Evaporator Area:

Condenser Area:

Fans:

Anti-Sweat Heaters:

Refrigerant Line Heat:

System COP:
17.7 cubic feet

8.0 for walls

7.4 for doors

$56 \%$ of Storage Volume

59.5 in.

32.0 in.

27.8 in.

56.3 square feet

Reciprocating, 5.28 EER

1.42 square feet per cubic foot

0.51 square feet per cubic foot

28.0 watts

5.5 watts

Vapor Line

1.36 
Table 13. Changes Made to EPA Baseline Refrigerator Characteristics

\begin{tabular}{|l|c|c|}
\hline \multicolumn{1}{|c|}{ Item } & EPA Report & Present Study \\
\hline Ambient temperature & $90^{\circ} \mathrm{F}$ & $75^{\circ} \mathrm{F}$ \\
\hline Temperature under cabinet & $105^{\circ} \mathrm{F}$ & $90^{\circ} \mathrm{F}$ \\
\hline $\begin{array}{l}\text { Temperature of air entering } \\
\text { condenser }\end{array}$ & $95^{\circ} \mathrm{F}$ & $80^{\circ} \mathrm{F}$ \\
\hline $\begin{array}{l}\text { Door opening: } \\
\text { Fresh food } \\
\text { Freezer }\end{array}$ & 0 & 2.5 per hour \\
\hline Fresh food temperature* & 0 & $38^{\circ} \mathrm{F}$ \\
\hline Freezer temperature* & $38^{\circ} \mathrm{F}$ & $5^{\circ} \mathrm{F}$ \\
\hline Total kWh/year & $5^{\circ} \mathrm{F}$ & 671 \\
\hline
\end{tabular}

* Note, these items were not changed for the present simulation.

Refrigerator simulations were performed for a range of filled evacuated panel characteristics. Filler resistivities used were $25 \mathrm{R} /$ inch and $50 \mathrm{R} /$ inch $(50 \mathrm{R} /$ inch is the highest value that the program will allow at present). The thickness of the stainless steel cladding ranged from 0.002 to 0.012 inches, and its thermal conductivity was taken to be $0.11,0.13$, and 0.15 $\mathrm{W} / \mathrm{cm} \cdot{ }^{\circ} \mathrm{C}$. The value of $0.13 \mathrm{~W} / \mathrm{cm}^{\circ}{ }^{\circ} \mathrm{C}$ corresponds to the average thermal conductivity measured in Section 3.1. The other two values are 15 percent higher and lower than the average, and represent the range of uncertainty in the measured values. Simulations were also performed for polymer-clad evacuated panels. Overall panel thicknesses were one-half inch and one inch, and the panels were assumed to cover 60 percent of the outside area of the refrigerator. A coverage of 60 percent is the value that has been estimated by the refrigerator industry as a practical limit 
considering the other components that must be placed within the walls and doors. The remaining space within the walls and doors of the refrigerators was taken to be filled with polyurethane foam insulation with a $R /$ inch of about 8 .

Figures 29 and 30 show the calculated annual energy usage for the refrigerator when insulated with a combination of polyurethane foam and evacuated panels at one-half inch and one inch thicknesses. The energy usages for polymer-clad panels are shown on these figures at zero cladding thickness. The reference case with no evacuated panel is also shown. The results show the expected decrease in energy usage as the evacuated panel resistivity is increased, as the panel thickness is increased, as the cladding thickness is decreased, and as the cladding thermal conductivity is decreased. Figure 29 shows that the cladding thickness for a one-half inch thick stainless-steel-clad panel with R-50 per inch filler must be less than about 0.007 inches in order to have an energy usage lower than a polymer-clad panel with an R-25 per inch filler of the same thickness. Since R-25 per inch fillers, such as precipitated silica, can be encapsulated in polymer claddings, this result places an upper limit on the stainless steel thickness that can be used and still allow the steel-clad higher R-per-inch fillers to be competitive. For one inch thick panels, the limit on stainless steel cladding thickness is about 0.004 inches.

\subsubsection{Economic Analysis}

The annual energy usages were used in a life-cycle analysis to calculate the present value of the lifetime energy savings produced by addition of evacuated panels to the doors and walls of the refrigerator. These calculations were based on a 20 year lifetime, a national average residential electricity price of 8.4 cents per kilowatt-hour [17], projections of future price changes for electricity [18], and a real (i.e., exclusive of inflation) discount factor of 3.4 percent [18]. It isinteresting to note that the price of electricity (exclusive of general inflation) over the next 20 years is projected to be no higher than the present price, and in some years to be one to two percent lower. Results of these calculations are given in Figures 31 and 32 for the one-half inch and one-inch thick evacuated panels. The present value of energy savings represents the benefit to the consumer, and places a limit on the extra price that a consumer should be expected to pay for a refrigerator that incorporates evacuated panels. This extra price is exclusive of any extra 
Energy Usage of 18 Cubic Foot Refrigerator

\subsection{Inch Thick Evacuated Panels at 60 percent Coverage}

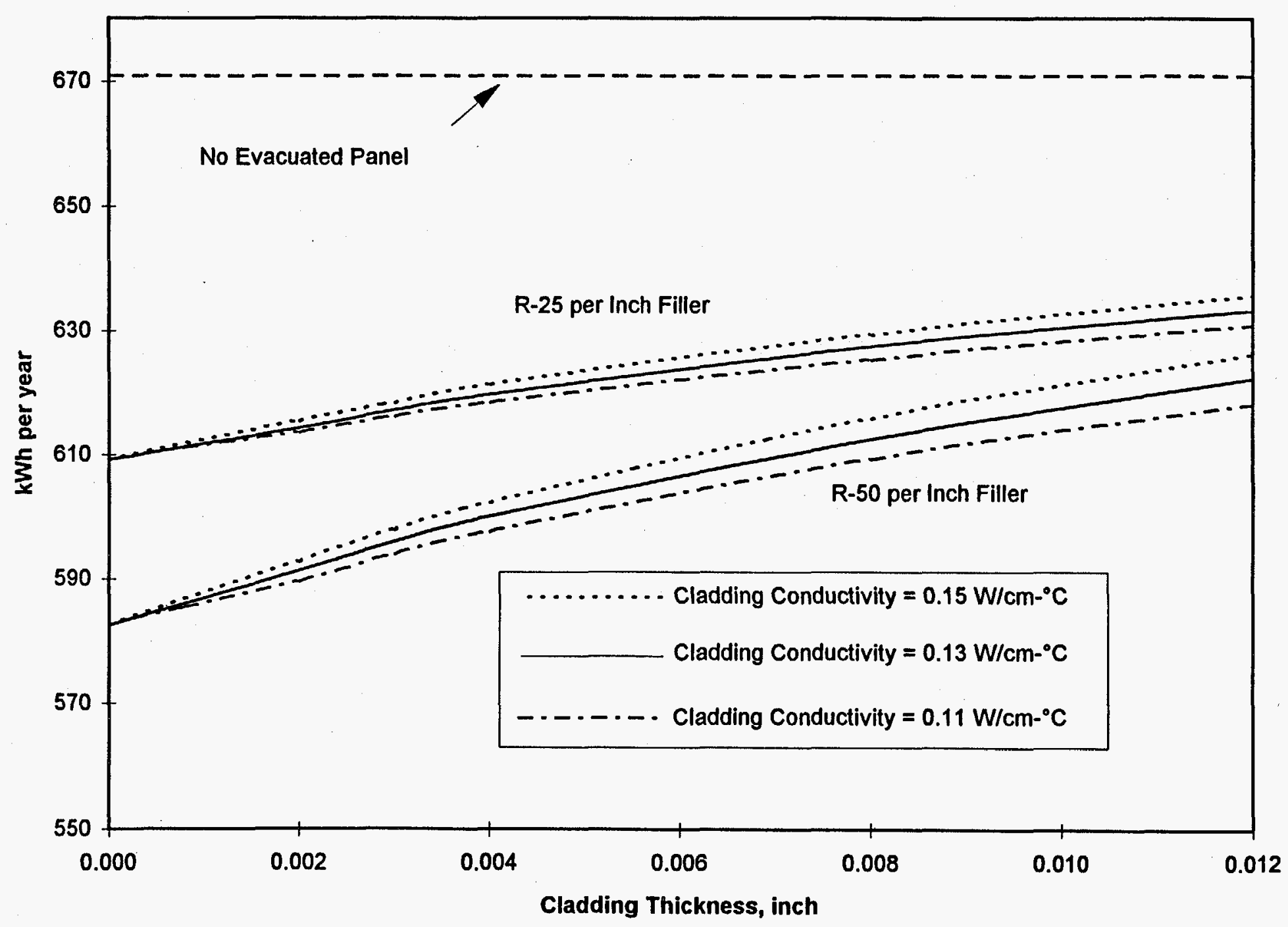

Figure 29. Calculated Annual Energy Usage for Refrigerator with 0.5 Inch Thick Evacuated Panels 


\section{Energy Usage of 18 Cubic Foot Refrigerator 1 Inch Thick Evacuated Panels at 60 percent Coverage}

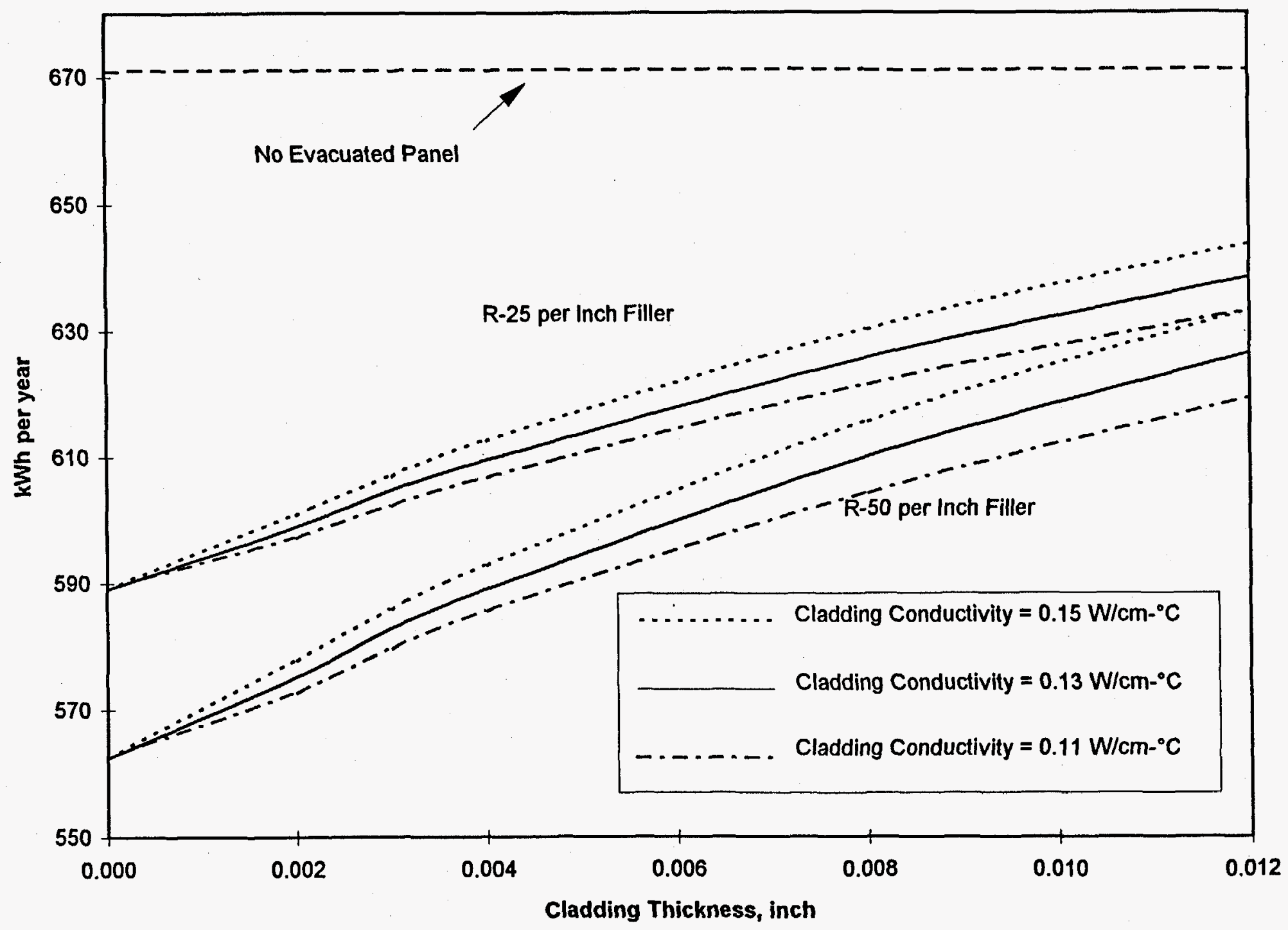

Figure 30. Calculated Annual Energy Usage for Refrigerator with 1 Inch Thick Evacuated Panels 


\section{Lifetime Value of Energy Savings for 18 Cubic Foot Refrigerator}

0.5 Inch Thick Evacuated Panels at 60 percent Coverage

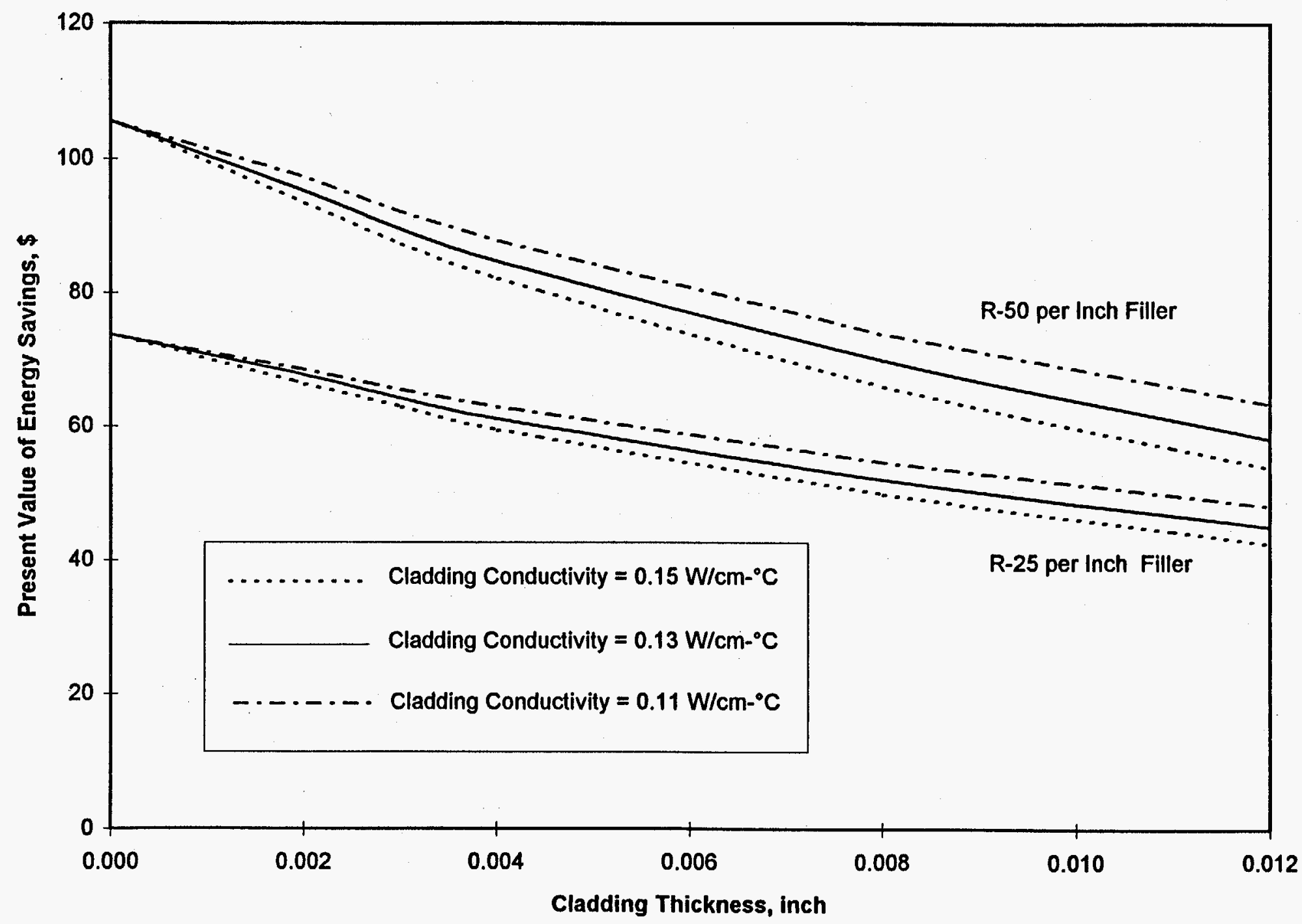

Figure 31. Calculated Lifetime Value of Energy Savings for Refrigerator with 0.5 Inch Thick Evacuated Panels 


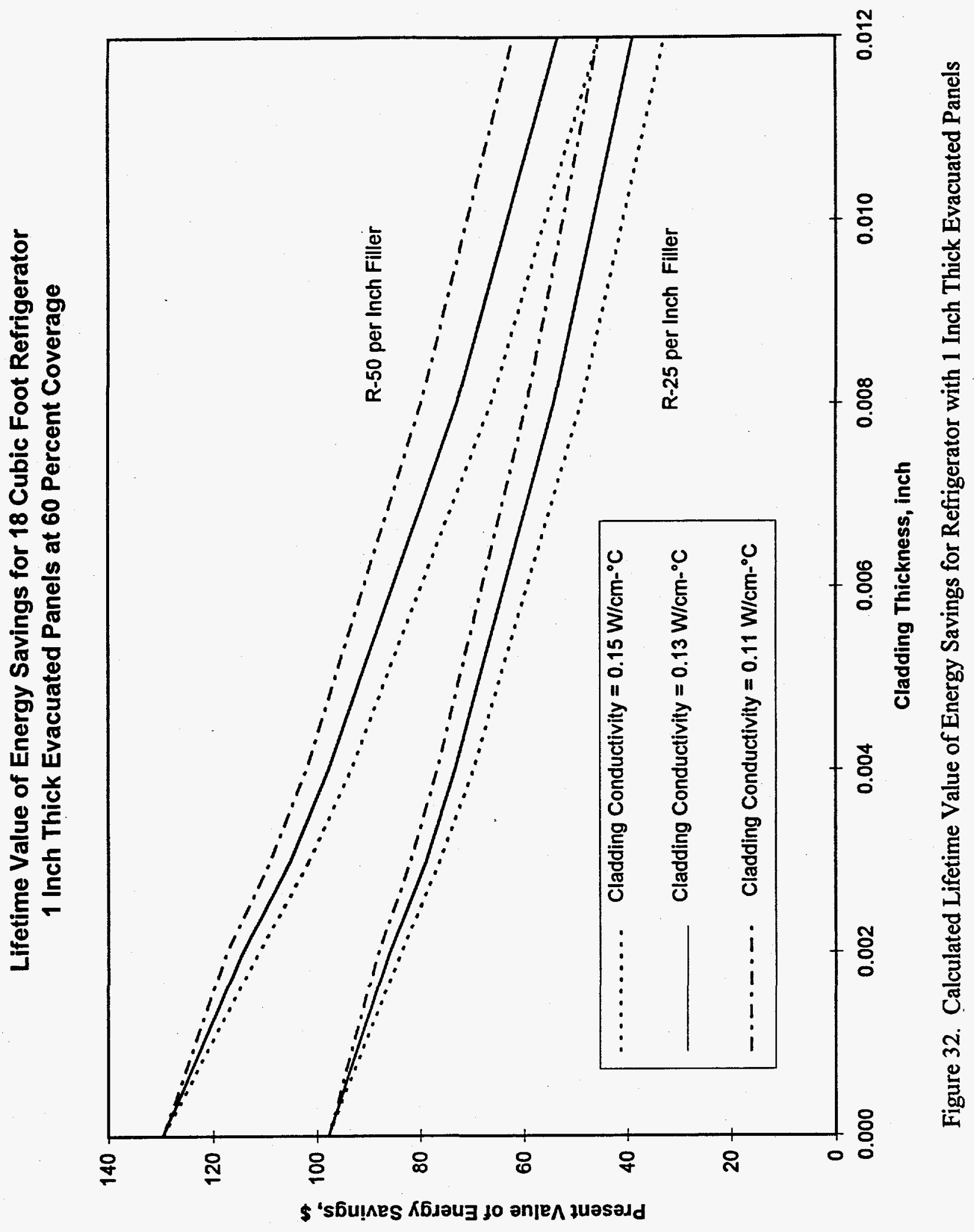


amount that a consumer might be willing to pay based on emotional or altruistic motivations due to factors such as contributing to reduction of greenhouse gases.

The present values of energy savings also can be used to estimate the additional material and manufacturing costs that can be allowed for the use of steel-clad, high-R-per-inch evacuated panels. As an example, we will take the case of one-inch-thick evacuated panels. For the 18 cubic foot refrigerator under study, the outside area is 56.3 square feet. With 60 percent coverage, 33.8 square feet of evacuated panels would be used. Waldron [19] estimated the incremental material and manufacturing costs for refrigerators insulated with polymer-clad, precipitated-silica-filled evacuated panels to be $\$ 1.39$ per board foot (i.e., one-inch thick and one square foot area) of panel. This figure includes the savings due to part of the polyurethane foam insulation being displaced by the evacuated panels. He estimated the cost of precipitated silica to be $\$ 0.75$ per board foot, while Aladdin estimates the cost of R-50 per inch fillers to be as low as $\$ 1.25$ per board foot. Waldron estimated that about 2.9 square feet of barrier would be used per board foot of panel and that the cost of polymer cladding would be about $\$ 0.32$ per board foot.

We assume that 2.9 square feet of stainless steel will also be required per board foot of panel, and estimate the cost of stainless steel to be $\$ 3.00$ per pound.

We adjusted Waldron's figure of $\$ 1.39$ per board foot to account for the differences in filler and cladding costs and calculated the incremental cost of adding stainless steel clad evacuated panels with R-50 per inch fillers to the typical refrigerator. The incremental energy savings and incremental costs of metal-clad panels are shown in Figure 33. Figure 33 shows that the cladding thickness must be less than about 0.004 inches thick in order to be economical. If profit margins were included in the analysis, the economical thickness would be less.

\section{INVENTIONS}

No inventions were made as part of this CRADA.

\section{COMMERCIALIZATION POSSIBILITIES}

Superinsulations based on filled evacuated panels are presently being commercialized. Some refrigerator manufacturers are utilizing superinsulations in certain models of refrigerators. 


\section{Incremental Benefits and Costs of Stainless Steel Clad Evacuated Panels}

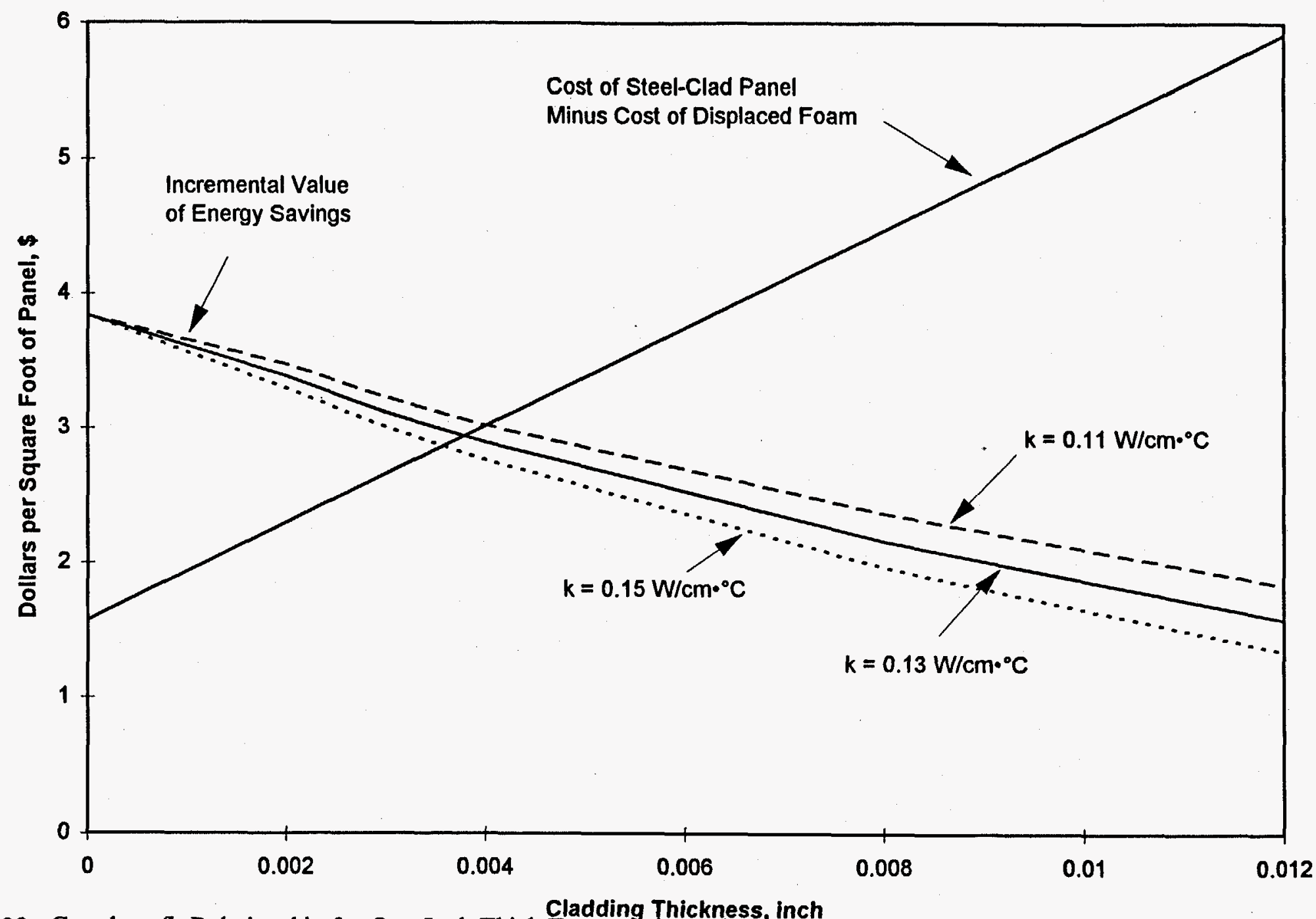

Figure 33. Cost-benefit Relationship for One-Inch Thick Evacuated Panels with Stainless Steel Cladding and R-50 per Inch Filler Applied to Typical Refrigerator 
It is expected that they will find use in other applications in the future, including other appliances such as water heaters and ranges, commercial ovens, building envelopes, refrigerated railcars and trucks, and industrial applications.

\section{PLANS FOR FUTURE COLLABORATIONS}

While there are no definite plans for future collaborations, ORNL and Aladdin will continue to interact as the technology of filled evacuated panels continues to be developed.

\section{CONCLUSIONS}

A direct electrical heating method was used to measure the electrical resistivity, emittance, and thermal conductivity of a series of austenitic stainless foils being considered for use as the cladding of evacuated panel insulations. The specimens had thicknesses ranging from 0.002 to 0.012 inches, and were made from AISI Type 201, 201L, 304, and 321 stainless steels. Measured thermal conductivities for Types 201L, 304 and 321 were within about 15 percent of values recommended in the literature, while the measured values for Type 201 were about 20 percent lower than the recommended values. At room temperature, the thermal conductivities of the various specimens varied by a total of \pm 8 percent about an average value of $0.13 \mathrm{~W} / \mathrm{cm} \cdot{ }^{\circ} \mathrm{C}$. Based on these data, it appears that variations of thermal conductivity among various types and thicknesses of austenitic stainless steels are relatively minor.

Thermal resistances of seven steel-clad evacuated panels were measured in a heat flow meter apparatus. The panels had various fillers and had claddings made of different types and thicknesses of steel (stainless steel except for the flat side of one panel which was made of coldrolled steel). Measured center-of-panel resistivities ranged from 15 to $58 \mathrm{R} / \mathrm{inch}$ $\left(\mathrm{h} \cdot \mathrm{ft}^{2}{ }^{\circ} \mathrm{F} / \mathrm{Btu} \cdot \mathrm{in}\right.$.). A special purpose computer program was used to analyze the experimental heat flux data to estimate the resistivity of the filler material, the overall resistivity of the panel, and the cladding thermal conductivity. These calculations showed that heat conduction through the metal cladding has a large effect on the thermal performance of the panel. It was projected that a very large panel would have a thermal resistivity 10 to 95 percent higher than the center-ofpanel values measured on the 14 inch square test panels. It was also projected that the overall 
resistivity of the panels would be as much as 58 percent lower than the measured center-of-panel values. Attempts to estimate the thermal conductivity of the cladding from the measured heat flux data met with only limited success.

EPA's Refrigerator Analysis (ERA) computer program was used to estimate the energy savings that could be expected from the application of evacuated panel insulation to the walls and doors of a typical refrigerator. Energy savings were calculated for panels with different filler resistivities, cladding thicknesses and cladding thermal conductivities. Comparisons were made between stainless-steel clad panels with R-50 per inch fillers and polymer-clad panels with R-25 per inch fillers. The latter corresponds to silica filler which may be contained within polymer claddings. For one-half inch thick panels, it was estimated that the metal cladding would have to be thinner than 0.007 inches in order for the metal-clad panels to have greater energy savings than

the polymer-clad panels. For one inch thick panels, the cladding would have to be less than 0.004 inches.

The calculated energy savings were used in a life-cycle economic analysis to examine the cost-benefit relationships for stainless-steel-clad panels. The incremental lifetime energy savings and incremental costs were calculated for stainless-steel-clad panels with R-50 per inch fillers. It was estimated that the cladding thickness would have to be less than about 0.004 inches to have a positive net benefit for one-inch-thick panels.

\section{ACKNOWLEDGMENTS}

Funding for this CRADA was provided by Aladdin Industries, Inc. and the U.S. Department of Energy, Office of Buildings Energy Research, under contract number DE-ACO5960R22464 with the Oak Ridge National Laboratory, managed by Lockheed Martin Energy Research Corp.

\section{REFERENCES}

1. C 835, "Standard Test Method for Total Hemispherical Emittance of Surfaces From 20 to $1400^{\circ} \mathrm{C}$," in 1996 Annual Book of ASTM Standards, Vol. 04.06, pp. 405-414, American Society for Testing and Materials, Philadelphia (1996). 
2. F. Kolrausch, Akad dt. Wisse. Berlin Sitzber, Vol. 38, p. 711 (1899).

3. F. Kolrausch, Annln Phys., Vol. 1, p. 132 (1900).

4. D. R. Flynn, "Measurement of Thermal Conductivity by Steady-state Methods in which the Sample is Heated Directly by Passage of an Electric Current," in Thermal Conductivity, Vol. 1, pp. 241-300, R. P. Tye, ed., Academic Press, New York (1969).

5. R. E. Taylor, "Thermophysical Property Determinations Using Direct Heating Methods," in Compendium of Thermophysical Property Measurement Methods, Vol. 1, pp. 125-167, ed. by K. D. Maglić, A. Cezairliyan, and V. E. Peletsky, Plenum Press, New York (1984).

6. R. L. Burden and J. D. Faires, Numerical Analysis, 4th Ed., pp. 126-144, PSW-KENT Publishing Co., Boston (1989).

7. R. S. Graves, T. G. Kollie, D. L. McElroy, and K. E. Gilchrist, "The Thermal Conductivity of AISI 304L Stainless Steel,"International of Thermophysics, Vol. 12, pp. 409-415 (1991).

8. Metals Handbook, 10th Ed., Vol. 1, p. 843, American Society for Metals, Metals Park, Ohio (1990).

9. T. K. Chu and C. Y. Ho, "Thermal Conductivity and Electrical Resistivity of Eight Selected AISI Stainless Steels," Thermal Conductivity 15, Proceedings of the 15th International Thermal Conductivity Conference, Ed. by V. V. Mirkovich, pp. 79-104, Plenum Press, New York (1978).

10. R. H. Bogaard, CINDAS, private communication (March 1997).

11. E. M. Sparrow and R. D. Cess, Radiation Heat Transfer, p. 71, Brooks/Cole Publishing Company, Belmont, California (1966).

12. C 518, "Standard Test Method for Steady-State Heat Flux Measurements and Thermal Transmission Properties by Means of the Heat Flow Meter Apparatus," in 1996 Annual Book of ASTM Standards, Vol. 04.06, pp. 151-162, American Society for Testing and Materials, Philadelphia (1996).

13. ASHRAE Handbook of Fundamentals, p. 36.2, American Society of Heating, Refrigerating, and Air-Conditioning Engineers, Atlanta (1993).

14. "EPA Refrigerator Analysis (ERA) Program, User's Manual, Version 1.0," EPA-430-R-93007 (1993).

15. "Multiple Pathways to Super-Efficient Refrigerators," EPA-430-R-93-008, U.S. EPA, Global Change Division, Office of Atmospheric Programs, Washington, D.C. (1993). 
16. H. A. Fine, J. Lupinacci, and J. S. Hoffman, "Vacuum Panel and Thick Insulation for Refrigerator/Freezers: Two Technologies that Work," Proceedings of the ACEEE 1992 Summer Study, pp. 1-14, ACEEE, Berkeley, California (1992).

17. "Electric \$ales and Revenue, 1995," DOE/EIA-0540(95), Energy Information Administration, U.S. Department of Energy, Washington, D.C. (December 1996).

18. "Energy Price Indices and Discount Factors for Life-Cycle Cost Analysis 1997," S. R. Petersen, NISTIR 85-3273-11, U.S. Department of Commerce, Washington, D.C. (1997).

19. J. M. Waldron, "Vacuum Panel and Thick Wall Foam Insulation for Refrigerators: Cost Estimates for Manufacturing and Installation," U.S. Environmental Protection Agency, EPA/430/R-92/1 10 (1992). 



\section{DISTRIBUTION LIST}

1-10. Kenneth E. Wilkes, Principal Investigator, Bldg. 4508, MS 6092

11. Brian B. Bovee, OTT Business Manager, Bldg. 701SCA, MS 8242

12. William Painter, Science Technology Partnerships Office, Bldg. 5002, MS 6416

13-22. John E. Besser, Aladdin Industries, Inc., 703 Murfreesboro Road, Nashville, TN 37210

23. Arun Vohra, Department of Energy, EE-41, 1000 Independence Ave., S. W., Washington DC 20585

24-25. DOE, Office of Scientific and Technical Information, Office of Information Service, P.O. Box 62, Oak Ridge, TN 37831

26. Robert M. Poteat, Office of Patent Counsel, Bldg. FED, MS 8751

27. Pamela L. Gorman, DOE-ORNL Site Office, Bldg. 4500-N, MS 6269

28. Laboratory Records, Bldg. 4500-N, MS 6285

29-33. M\&C Records Office, Bldg. 4508, MS 6094 